\title{
Atmospheric impacts of the 2010 Russian wildfires: integrating modelling and measurements of an extreme air pollution episode in the Moscow region
}

\author{
I. B. Konovalov ${ }^{1,2}$, M. Beekmann ${ }^{2}$, I. N. Kuznetsova ${ }^{3}$, A. Yurova ${ }^{3}$, and A. M. Zvyagintsev ${ }^{4}$ \\ ${ }^{1}$ Institute of Applied Physics, Russian Academy of Sciences, Nizhniy Novgorod, Russia \\ ${ }^{2}$ Laboratoire Inter-Universitaire de Systèmes Atmosphériques, CNRS, UMR7583, Université Paris-Est and Université Paris 7 , \\ Créteil, France \\ ${ }^{3}$ Hydrometeorological Centre of Russia, Moscow, Russia \\ ${ }^{4}$ Central Aerological Laboratory, Dolgoprudny, Russia
}

Received: 15 March 2011 - Published in Atmos. Chem. Phys. Discuss.: 19 April 2011

Revised: 16 September 2011 - Accepted: 27 September 2011 - Published: 4 October 2011

\begin{abstract}
Numerous wildfires provoked by an unprecedented intensive heat wave caused continuous episodes of extreme air pollution in several Russian cities and densely populated regions, including the Moscow region. This paper analyzes the evolution of the surface concentrations of $\mathrm{CO}$, $\mathrm{PM}_{10}$ and ozone over the Moscow region during the 2010 heat wave by integrating available ground based and satellite measurements with results of a mesoscale model. The CHIMERE chemistry transport model is used and modified to include the wildfire emissions of primary pollutants and the shielding effect of smoke aerosols on photolysis. The wildfire emissions are derived from satellite measurements of the fire radiative power and are optimized by assimilating data of ground measurements of carbon monoxide (CO) and particulate matter $\left(\mathrm{PM}_{10}\right)$ into the model. It is demonstrated that the optimized simulations reproduce independent observations, which were withheld during the optimisation procedure, quite adequately (specifically, the correlation coefficient of daily time series of $\mathrm{CO}$ and $\mathrm{PM}_{10}$ exceeds 0.8 ) and that inclusion of the fire emissions into the model significantly improves its performance. The model results show that wildfires are the principal factor causing the observed air pollution episode associated with the extremely high levels of daily mean $\mathrm{CO}$ and $\mathrm{PM}_{10}$ concentrations (up to $10 \mathrm{mg} \mathrm{m}^{-3}$ and $700 \mu \mathrm{g} \mathrm{m}^{-3}$ in the averages over available monitoring sites, respectively), although accumulation of anthropogenic pollution was also favoured by a stagnant meteorological sit-
\end{abstract}

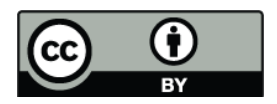

Correspondence to: I. B. Konovalov (konov@appl.sci-nnov.ru) uation. Indeed, ozone concentrations were simulated to be episodically very large ( $>400 \mu \mathrm{g} \mathrm{m}^{-3}$ ) even when fire emissions were omitted in the model. It was found that fire emissions increased ozone production by providing precursors for ozone formation (mainly VOC), but also inhibited the photochemistry by absorbing and scattering solar radiation. In contrast, diagnostic model runs indicate that ozone concentrations could reach very high values even without fire emissions which provide "fuel" for ozone formation, but, at the same time, inhibit it as a result of absorption and scattering of solar radiation by smoke aerosols. A comparison of MOPITT CO measurements and corresponding simulations indicates that the observed episodes of extreme air pollution in Moscow were only a part of a very strong perturbation of the atmospheric composition, caused by wildfires, over European Russia. It is estimated that 2010 fires in this region emitted $\sim 10 \mathrm{TgCO}$, thus more than $85 \%$ of the total annual anthropogenic CO emissions. About $30 \%$ of total $\mathrm{CO}$ fire emissions in European Russia are identified as emissions from peat fires.

\section{Introduction}

An unprecedented intensive heat wave provoked thousands of wildfires during summer of 2010 over European Russia. These fires had devastating consequences for forests, crops, and infrastructure (2010 Russian wildfires, 2011). The state of emergency was officially declared during these events in seven Russian regions. Several severe air pollution episodes occurred during this period in number of Russian regions and

Published by Copernicus Publications on behalf of the European Geosciences Union. 
large cities, including Moscow, Nizhniy Novgorod, Ryazan, Tula, Vladimir and Voronezh. Strong perturbations of atmospheric composition over Russia were clearly detectable from space (Witte et al., 2011; Yurganov et al., 2011).

From a scientific point of view, the extreme perturbation of atmospheric composition in summer 2010 over European Russia provided a critical test for the current understanding of atmospheric chemical and meteorological processes. Among numerous issues raised by this phenomenon, this paper focuses on the analysis of an extreme air pollution episode observed in the Moscow megacity region. The Moscow region is a highly urbanized territory with a total population exceeding 15 millions of inhabitants. Moscow is the Russian capital and the largest city in Europe. It is one of the major political, economic, cultural, and transportation centers of Europe and the world. Similar to many other megacities (Molina and Molina, 2004), Moscow experiences serious environmental problems, including air pollution (Zvyagintsev et al., 2004; Gorchakov et al., 2006; Konovalov et al., 2009; Kuznetsova et al., 2011), even under normal conditions.

Modeling of air pollution caused by predominantly anthropogenic sources has been a subject of a vast number of studies. Although the performance of current chemistry transport models (CTMs) is yet far from being perfect, it was demonstrated (see e.g. Vautard et al., 2007) that in many instances they are capable of reproducing and predicting important features of the observed evolution of major air pollutants. On the other hand, emissions from wildfires are usually not taken into account in standard configurations of most regional CTMs, and thus they are not directly applicable in situations where the role of wildfires may be significant. Meanwhile, there is a bulk of evidence that wildfires may have a strong impact on air quality (see e.g. Langmann et al., 2009 and references therein). A major factor hampering progress in modeling effects of wildfires on air pollution is the lack of sufficiently accurate estimates of gaseous species and aerosol emissions from these fires.

Available methods to obtain fire emission estimates have been discussed in numerous papers. The most common approach to derive fire emissions is based on the use of information on the burned area (e.g. Seiler and Crutzen, 1980; Crutzen and Andreae, 1990; Andreae and Merlet, 2001; Hao et al., 1996; van der Werf et al., 2006, 2010; Jain et al., 2006). Apart from the burned area estimates which, in recent years, have become available from satellite measurements (e.g. Grégoire et al., 2003; Giglio et al., 2006), this approach requires additional data characterizing the local biome and the available fuel load, which, in many instances, are rather uncertain.

Ichoku and Kaufman (2005) suggested a different approach to obtain fire emission estimates, which is based on a direct empirical relationship between fire radiative power (FRP) retrieved from satellite measurements and the instantaneous rate of biomass burning. Using the Moderate Reso- lution Imaging Spectroradiometer (MODIS) active fire product, they demonstrated linear correlations between FRP and the smoke aerosol emission rate derived from aerosol optical thickness data by means of a simple mass balance model. They also estimated the smoke emission coefficient which can be simply multiplied by FRP to calculate the smoke aerosol emission rate. In particular, the magnitude of this coefficient for Western Russian regions was found to be in the range from 0.08 to $0.1\left(\mathrm{~kg} \mathrm{MJ}^{-1}\right)$, although it was admitted that this result could be overestimated by about 50 percent due to different uncertainties in the data and analysis. Wooster et al. (2005) analyzed results from a series of experimental fires conducted to calibrate relationships between radiated energy and fuel consumption. They found that the relationship between FRP and fuel consumption is linear with the proportionality coefficient of $0.368( \pm 0.015) \mathrm{kg} \mathrm{MJ}^{-1}$. This approach seems to be very suitable for near real time data assimilation systems (Sofiev et al., 2009; Kaiser et al., 2009), particularly because it allows (at least, in principle) estimating emissions from currently active fires and taking into account differences in smoke emission rates from different active fire pixel. However, it should be noted that the emission estimates which can be derived from FRP measurements are not yet sufficiently validated; further work aimed at elucidating possible uncertainties in such estimates is needed, including comparisons with data of traditional fire emission inventories. A comparison (Roy et al., 2008) of the MODIS burned area product with the alternative burned area estimates obtained by mapping the MODIS active fire data revealed a large difference (up to a factor of two) between the continentally averaged data; these results can be regarded as indirect evidence that the emission estimates obtained with the two approaches discussed above can also be very different. In this study, we follow the approach suggested by Ichoku and Kaufman (2005), having in mind prospects of operational applications of our modeling system for air quality forecasts and air pollution control in Russia (Kuznetsova et al., 2010). Note that development of a modeling system which could enable analysis and forecasting of air pollution in the Moscow region during intensive fire events is practically important, taking into account that episodes of strong air pollution associated with wildfires were already observed in this region in the past (see e.g. Chubarova et al., 2009) and will probably happen again in the future.

Wildfire emission estimates obtained with the burned area approach have been used in many global modeling studies addressing effects of wildfires on atmospheric composition (see e.g. Park et al., 2003; Jeong et al., 2008; Turquety et al., 2007; Pfister et al., 2008; Stavrakou et al., 2009). The reduction of potential uncertainties in global model results can be achieved by averaging model outputs over sufficiently large areas and/or long (e.g. monthly) time periods. This way would not be practical in the case of regional air pollution models, as they are expected to address much finer temporal and spatial scales dictated by the necessity to simulate 
regional air pollution episodes. Accordingly, more accurate emission data are typically needed in the case of regional CTMs. It is not surprising then that comparisons of simulations performed by regional CTMs employing wildfire emission data with air pollution measurements have so far been presented in very few papers. Specifically, Wang et al. (2006) used the Regional Atmospheric Modeling System (RAMS) which did not include atmospheric chemistry and secondary aerosol formation to simulate the transport of smoke aerosols from Central America to US. A particular goal of their study was to examine the impact of including diurnal variations of fire behavior on smoke transport simulated by RAMS. They found that the simulated aerosol concentrations correlate well with corresponding monitoring data but are much smaller than observations. Unexpectedly, they found also that including diurnal variations of wildfire emissions did not improve the agreement between simulations and measurements. Hodzic at al. (2007) compared aerosol optical properties simulated by the CHIMERE CTM with those derived from the MODIS and POLDER satellite measurements. They demonstrated the ability of the model to adequately reproduce perturbations of aerosol optical thickness (AOT) caused by the advection of a smoke plume from the source region in Portugal to Northern Europe. However, inclusion of fire emissions in the model did not allow improving temporal variability of AOT data at specific locations of the AERONET monitoring network. Larkin et al. (2009) presented a modeling framework enabling simulations of the cumulative smoke impacts from fires across the USA. They showed that the modeled output generally compared well with satellite plume observations, but underpredicted measured $\mathrm{PM}_{2.5}$ concentrations during the considered episode. While Wang et al. (2006), Hodzic et al. (2007) and Larkin et al. (2009) used wildfire emission inventories based on the burned area approach, Sofiev et al. (2009) derived aerosol fire emissions from FRP measurements. Their emission estimates were then used in the SILAM CTM to simulate $\mathrm{PM}_{2.5}$ concentrations and columns. They have demonstrated similarity of spatial distributions in simulations and measurements during selected episodes of intensive fires in Europe, but the temporal evolution of the simulated $\mathrm{PM}_{2.5}$ concentrations and columns was not quantitatively evaluated.

Here we use the CHIMERE CTM and air quality monitoring data to examine the feasibility of using pyrogenic emission estimates derived from satellite FRP measurements to simulate daily variability of air pollution in a megacity region during a period of intensive wildfires in summer 2010 . The important features of the situation addressed in this study are strongly perturbed (by smoke) optical properties of the atmosphere and significance of peat fires which could be neglected in the situations addressed by Sofiev et al. (2009). These features make direct estimation of fire emissions from FRP difficult, and ways to overcome these difficulties are proposed. One of the ideas exploited in this study is to use an inverse modeling approach to optimize scaling factors used to convert FRP to the biomass burning rate. We also evaluate the impact of wildfires on air quality in the Moscow megacity region during this period. A distinctive feature of this study is a parallel analysis of the evolution of several major pollutants of both primary and secondary origin $\left(\mathrm{CO}, \mathrm{PM}_{10}\right.$, $\mathrm{O}_{3}$ ). Such an approach allows us not only to evaluate wildfire emission estimates, but also to examine the ability of a typical regional CTM to simulate complex processes driving formation of secondary pollutants in a strongly polluted atmosphere.

\section{Measurement data}

\subsection{Satellite measurements}

\subsubsection{Fire radiative power (FRP)}

FRP is retrieved from the measurements performed by MODIS instruments on board of NASA polar orbiting Aqua and Terra satellites (Ichoku and Kaufmann, 2005). The nominal resolution of FRP measurements by MODIS is about $1 \mathrm{~km}^{2}$.

We used the standard MODIS data products, which are publicly distributed by the Land Processes Distributed Active Archive Center (LP DAAC) through the Earth Observing System Clearing House (ECHO, http://www.echo.nasa.gov/) system as Level 2 (orbital) and Level 3 (gridded) products. The algorithm of FRP retrieval (Kaufmann et al., 1998) is based on an empirical relationship between FRP and temperature measured at the $4 \mu \mathrm{m}$ MODIS channel in a pixel with fires and an adjacent "background" pixel without fires $\left(T_{4 \mathrm{f}}\right.$ and $T_{4 \mathrm{~b}}$, respectively):

$\mathrm{FRP} \cong 4.34 \times 10^{-13}\left(T_{4 \mathrm{f}}^{8}-T_{4 \mathrm{~b}}^{8}\right)[\mathrm{Watt}]$

This dependence was obtained by fitting the simulated energy released from many pixels with fires as a function of average radiance at $4 \mu \mathrm{m}$. Each pixel contained 500 zones with different physical temperature representing both smoldering and flaming fires, and the standard deviation in the derived fire energy is estimated as $16 \%$ on the average (Kaufmann et al., 1998). However, there are many factors that may lead to much larger uncertainties in real FRP measurement data. Among these factors are clouds and aerosol that may attenuate infrared radiation detected by a satellite instrument and dilute the contrast between the background and fire pixels. Estimation of FRP from space is especially difficult or impossible for fires overshadowed by trees and for subsurface smoldering fires (peat fires). All these factors may cause negative biases in the FRP retrievals.

The polar orbiting Aqua and Terra satellites cannot provide sufficient information about the diurnal cycle of fire activity. For this reason, a fixed diurnal profile of FRP, $p_{\mathrm{h}}(t)$, is assumed, which was adopted from WRAP (2005) (see Fig. 1). Hodzic et al. (2007) used the same profile and found 


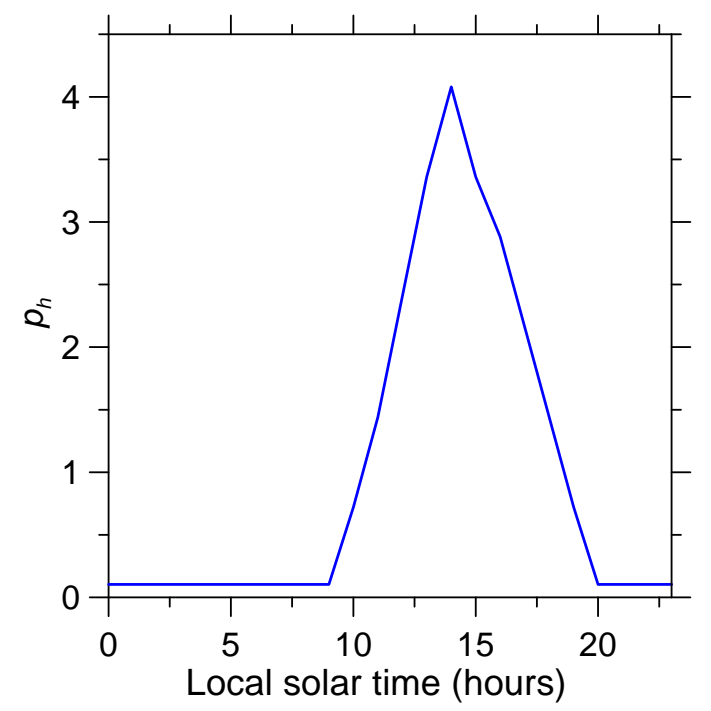

Fig. 1. The diurnal profile of emissions from wildfires, $p_{\mathrm{h}}$ (see Eq. 3), which is used to convert MODIS FRP measurements to hourly emissions of model species.

that "hourly resolution of wildfire emissions gives better results" (compared to the case of the daily resolution) "when simulating the impact of large wildfire events and comparing the modeling data with satellite observations dominated by biomass burning aerosols".

The Level 2 FRP data (MOD14/MYD14) were projected to a regular grid (with a resolution of $0.2^{\circ} \times 0.1^{\circ}$ for longitude and latitude). This resolution corresponds to that of our model grid employed for regional-scale simulations. Specifically, for each orbit $k$ we defined a spatially averaged FRP density, $\Phi_{k}$, corresponding to a given cell of the output grid as follows:

$\Phi_{k}=\frac{\sum_{j} \mathrm{FRP}_{j k}}{\sum_{j} S_{j k}^{\mathrm{f}}+S_{k}^{\mathrm{c}}}$,

where $j$ is the index of an observed pixel falling into the considered grid cell, $\mathrm{FRP}_{j k}$ and $S_{j k}^{\mathrm{f}}$ are FRP (MW) and the area $\left(\mathrm{km}^{2}\right)$ of the fire pixel, respectively, and $S_{k}^{\mathrm{c}}$ is the total observed area of the surface (in the considered grid cell) identified in MODIS measurements as water and non-fire clear land. An area for which observational information about potential fire activity is not retrieved (because of clouds or any other reasons) is not taken into account in $S_{k}^{\mathrm{c}}$. To avoid technical difficulties associated with obtaining and processing of huge amount of geolocation data needed to estimate $S_{k}^{\mathrm{c}}$ from Level 2 data, we have derived $S_{k}^{\mathrm{c}}$ from the Level 3 daily data product (MOD14A1/MYD14A1) provided on a $1 \times 1 \mathrm{~km}^{2}$ grid. This simplification may entail some random uncertainties in $\Phi$ due to possible inconsistencies between the observed area identified at a given overpass of a satellite and the area reported in the daily data product. However, this kind of a possible error is hardly significant in comparison with other inevitable uncertainties in the measured FRP data.

The goal of the next step is to obtain estimates for daily mean values of FRP, $\Phi_{\mathrm{d}}$. One possibility is averaging all FRP orbital data available for a given day. However, we have found that this way leads to strongly underestimated (by more than an order of magnitude) emissions of air pollutants, probably because of the contribution of scenes partly obscured by clouds but not entirely disregarded in the FRP retrievals. Instead, only a maximum value among values of $\Phi_{k}$ observed in a given grid cell and during a given day $d$ is taken into account:

$\Phi_{\mathrm{d}}=\max \left\{\Phi_{k}, k=1, \ldots K\right\} p_{\mathrm{h}}\left(t_{\max }\right)^{-1}$

where $K$ is the total number of scans during the given day, and $p_{\mathrm{h}}\left(t_{\mathrm{max}}\right)$ is the weighting factor accounting for the assumed diurnal variation of FRP; $t_{\max }$ is the moment when the scan with the maximum FRP was done.

\subsubsection{Aerosol optical depth (AOD)}

Similar to the FRP data described above, the AOD data used in this study are retrieved from measurements performed by the MODIS satellite instrument. Specifically, we make use of the aerosol optical depths at $550 \mathrm{~nm}$ provided as the Level 3 daily data (MYD08_D3) gridded with a spatial resolution of $1 \times 1^{\circ}$. In this study, grid cells with missing data are filled in by spatial averaging over an area of 5 by $5^{\circ}$. For the period considered in this study, only AQUA AOD measurements were available. A description of the retrieval procedure can be found in Kaufmann et al. (1997). The estimated relative uncertainty of the MODIS AOD data over land is about $20 \%$ and the absolute part of errors ranges within \pm 0.05 (Ichoku et al., 2005).

\subsubsection{CO mixing ratio}

We use CO mixing ratios derived from infrared radiance measurements which are performed by the MOPITT instrument onboard the NASA Terra satellite. The MOPITT retrievals (version V4) include CO mixing ratio for a floating surface level followed by nine uniformly spaced levels from 900 to $100 \mathrm{hPa}$. Only data for $900 \mathrm{hPa}$ pressure level are considered in this study. It should be noted that the information provided in the MOPITT data product for the given level actually comes from all levels although with different weights specified by the corresponding averaging kernels (see e.g. Pfister et al., 2004). In other words, the retrieved mixing ratios at any level are a result of a certain non-uniform transformation of the actual vertical distribution of the $\mathrm{CO}$ mixing ratio. We use the Level 3 daily data (MOP03) given on a $1^{\circ} \times 1^{\circ}$ grid. Only daytime data are considered in this study because they provide more information about boundary layer processes simulated by our model. 


\subsection{Ground based measurements}

We use measurements of $\mathrm{CO}, \mathrm{PM}_{10}$ and $\mathrm{O}_{3}$ near-surface concentrations in the Moscow region, which were made at automatic monitoring stations of the State Environmental Institution "Mosecomonitoring". The nominal measurement frequency was three measurements per hour. Infrared spectrometry, ultraviolet fluorescence and TEOM methods were used for measurements of carbon monoxide, ozone and particulate matter, respectively. Most of the monitoring sites are located within boundaries of Moscow city, but there are also a few sites in Moscow suburbs (specifically, in Zvenigorod, Zelenograd, and Pavlovskii Posad). Further information about the Mosecomonitoring air pollution monitoring network can be found on web (www.mosecom.ru).

The selection of monitoring sites considered in this study was based on their spatial representativeness and the total number of available measurements. Specifically, we consider only "residential" and "background" monitors providing more than $50 \%$ of days with the measurements during the analyzed period (from 1 June to 31 August). Road traffic and industrial sites are excluded from analysis. The total numbers of selected monitoring sites are 17, 7, and 8 for $\mathrm{CO}$, $\mathrm{PM}_{10}$, and $\mathrm{O}_{3}$, respectively. Additionally, sites measuring $\mathrm{CO}$ and $\mathrm{PM}_{10}$ were distributed randomly into two groups. One group is used for optimization of wildfire emissions used in our model, while the other is used only for validation of simulations. Note that we do not expect that the variability of concentrations at optimization and validation sites is independent. On the contrary, the purpose of the validation procedure is to insure that the set of measurement sites used for optimization of emissions is, on the average, sufficiently representative of the whole region. The groups used for optimization include respectively 9 and $4 \mathrm{CO}$ and $\mathrm{PM}_{10}$ monitors. $\mathrm{O}_{3}$ measurements were not used in the optimization procedure; therefore, all measurement data from the selected $\mathrm{O}_{3}$ monitors were used for validation. The location of the selected $\mathrm{CO}, \mathrm{PM}_{10}$ and $\mathrm{O}_{3}$ monitors in Moscow is shown in Fig. 2.

To simplify our analysis, we consider time series of daily mean $\mathrm{CO}$ and $\mathrm{PM}_{10}$ concentrations averaged over all sites in a given group. This is a logical approach in our case, taking into account that most of the monitors are situated within $20 \mathrm{~km}$ from the Moscow center and that this study does not address spatial variations of pollutant concentrations inside of the Moscow agglomeration.

Ozone concentrations measured in Moscow exhibit very strong spatial variability on fine scales (probably as a result of ozone titration by strong NO emissions in Moscow) which cannot be adequately addressed by our model. In such a situation, the model is expected to better predict the largest ozone concentration over the region than a spatially averaged concentration. It should also be taken into account that the model provides outputs on the hourly basis and the air quality standards in Russia regulate the daily maximum ozone concentration with the threshold value of $160 \mu \mathrm{g} \mathrm{m}^{-3}$. Accordingly, we construct a time series of daily values of measured ozone concentrations by selecting (for each day) a site with the largest daily maximum of 1-h mean ozone concentrations. A given day is taken into account only if measurements are provided for 20 or more hourly counts.

\section{Simulations}

\subsection{CHIMERE chemistry transport model: general description and numerical experiment settings}

We used the CHIMERE chemistry transport model (V2007), which is a multi-scale three-dimensional model designed to simulate air pollution in the boundary layer and free troposphere at regional and continental scales. Evaluation and description of the initial version of this model was presented by Schmidt et al. (2001). Since then the model has been used in numerous studies (e.g. Hodzic et al, 2005, 2007; Vautard et al., 2007; Bessagnet et al., 2008; Menut et al., 2009; Konovalov et al., 2008, 2010; Rouil et al., 2009; Beekmann and Vautard, 2010), while the model code permanently undergoes further developments and modifications. Along with sufficiently comprehensive (although simplified) representations of atmospheric gas-phase chemistry and transport, the model includes parameterisations of major processes driving formation and evolution of organic and inorganic aerosols (such as nucleation, condensation, coagulation, dry and wet deposition, and windblown dust generation). An in-detail description of the model can be found in the CHIMERE technical documentation available on the web (http://www.lmd.polytechnique.fr/chimere/).

In this study, simulations were performed using a nesteddomain approach. Specifically, we used a large domain covering both Western and Eastern Europe with a coarse resolution of $1^{\circ} \times 1^{\circ}$ and a small (nested) domain covering only a central part of European Russia (including the Moscow region) with the finer resolution of $0.2^{\circ} \times 0.1^{\circ}$. Simulations of the atmospheric composition by CHIMERE over Eastern Europe were evaluated earlier (Konovalov et al., 2005, 2009; Kuznetsova et al., 2010, 2011). It was found, in particular, that in spite of potentially large uncertainties in the anthropogenic emission inventory data for Eastern Europe, CHIMERE demonstrates similar performance in both Western and Eastern parts of Europe (Konovalov et al., 2005), probably because emission uncertainties are not a major factor limiting the performance of this model (Konovalov et al., $2006 a, b)$. In the vertical dimension, the simulations were performed with 12 vertical levels specified in hybrid coordinates with the resolution decreasing from bottom to top in accordance with a geometrical progression. The top of the CHIMERE vertical domain is fixed at the $200 \mathrm{hPa}$ pressure level. Boundary conditions for gaseous and aerosol species are specified by using monthly average ("climatological") 

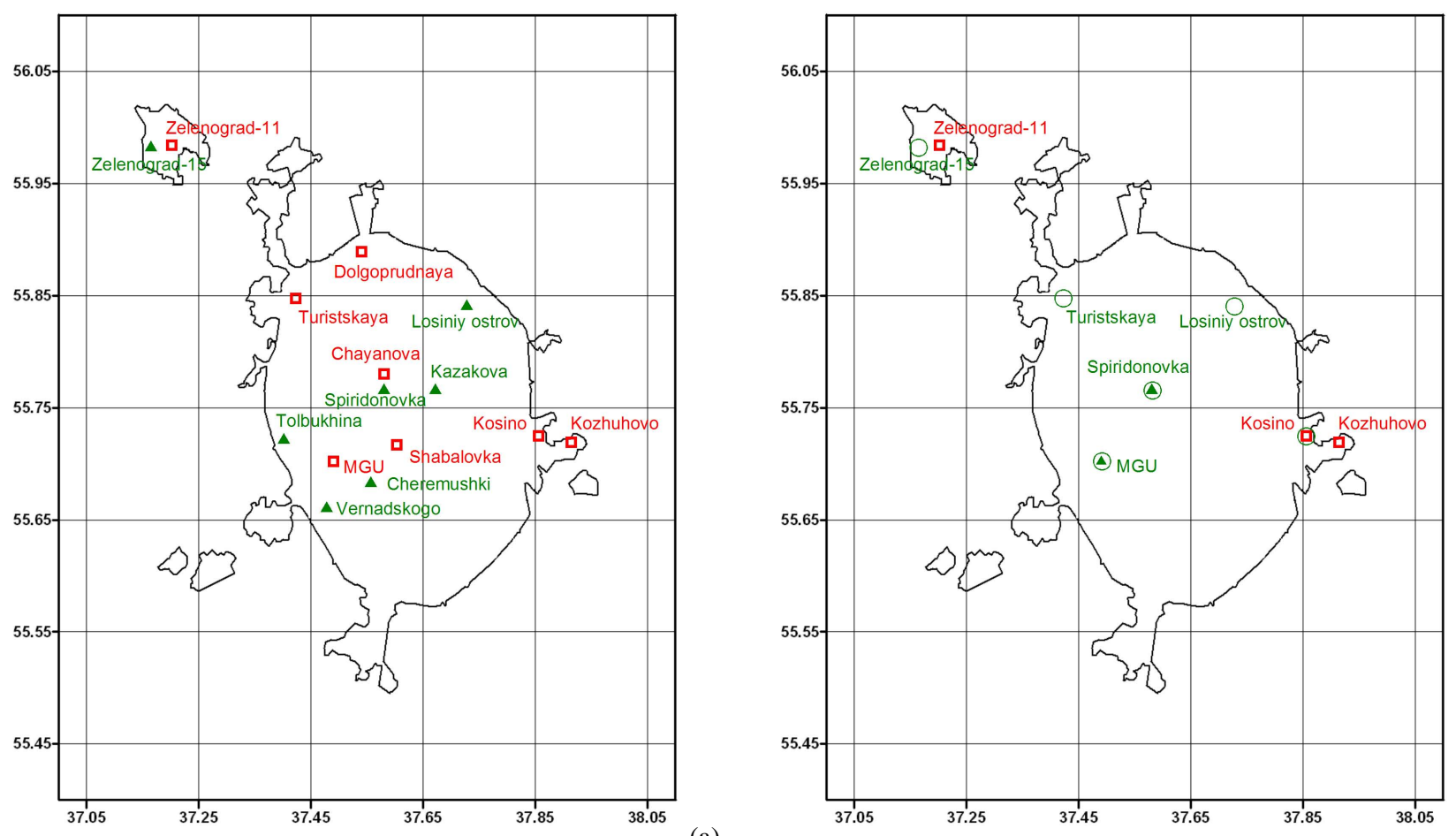

(a)

Fig. 2. The maps illustrating the location of air pollution monitors selected for this study: (a) $\mathrm{CO}$ monitors; (b) $\mathrm{PM}_{10}$ and $\mathrm{O}_{3}$ monitors. Red squares and green triangles represent, respectively, the optimisation and validation subsets of $\mathrm{CO}$ and $\mathrm{PM}_{10} \mathrm{monitors}$ which were randomly selected from the full set of "residential" and "background" monitors (see Sect. 2.2). Ozone monitors (used for validation only) are represented by green circles. Not shown are monitoring stations (measuring $\mathrm{CO}, \mathrm{PM}_{10}$, and $\left.\mathrm{O}_{3}\right)$ in Pavlovskii Posad ( $\sim 50 \mathrm{~km}$ east of Moscow) and in Zvenigorod ( $\sim 40 \mathrm{~km}$ west of Moscow). Observations in Pavlovskii Posad were used for optimisation of CO and PM 10 emissions and for validation of $\mathrm{O}_{3}$ simulations, while measurement data from the Zvenigorod station were used for validation of $\mathrm{CO}$, $\mathrm{PM}_{10}$ and $\mathrm{O}_{3}$ simulations.

values of the MOZART (Horowitz et al., 2003) and GOCART (Ginoux et al., 2001) models, respectively.

Meteorological input data were calculated off-line with a horizontal resolution of $100 \times 100 \mathrm{~km}^{2}$ using the MM5 non-hydrostatic meso-scale model (http://www.mmm.ucar. edu/mm5/). MM5 was initialised with NCEP Reanalysis-2 data (http://www.cpc.ncep.noaa.gov/products/wesley/ncep_ data/). The resolution of MM5 was defined taking into account available computational resources and results of the study by Zaripov et al. (2011), in which no serious difference in accuracy of ozone forecasts produced by CHIMERE for the Moscow region was found when resolution of meteorological data decreased from $20 \times 20 \mathrm{~km}^{2}$ to $70 \times 70 \mathrm{~km}^{2}$. A probable explanation of this result is that the accuracy of higher resolution meteorological simulations for the considered plain region is mainly limited by global data driving mesoscale simulations. Possible effects of perturbations in the atmospheric radiative balance due to changes in atmospheric composition (in particular due to the large aerosol content owing to fires) could not be properly addressed in our modelling scheme. In a less direct way, they were taken into account in the NCEP Reanalysis-2 data through assimilation of measured data.
Simulations were performed with the MELCHIOR1 gas phase chemical mechanism (Lattuati, 1997) which includes more than 300 reactions of 80 species. Parameterisation of a minimal set of heterogeneous reactions specified in CHIMERE as recommended by Jacob (2000) is based on formulations of Aumont et al. (2003) and is mainly applicable to anthropogenic urban aerosol, while in our case most of aerosol is produced by wildfires. Major modifications of this simple parameterization are also needed in view of recent experimental findings (Monge et al., 2010) revealing that heterogeneous processes are strongly affected by solar radiation. Accordingly, as a conservative option, all heterogeneous reactions in our simulations were disregarded. A special model test run which was performed with the "standard" parameterisation to roughly assess the potential role of heterogeneous reactions in the considered phenomenon indicated that in general it was not important, although not always negligible (e.g. corresponding changes in ozone concentration mostly did not exceed a few percent but reached a few tenths of percent on one day, 7 August, associated with the largest concentration of smoke aerosol).

Calculations of photolysis rates in the CHIMERE standard version are based on the tabulated outputs from 
Table 1. Summary of settings of different model runs performed in the framework of this study.

\begin{tabular}{llll}
\hline $\begin{array}{l}\text { Model run names } \\
\text { (abbreviation) }\end{array}$ & Fire emissions & $\begin{array}{l}\text { Aerosol impact on } \\
\text { photolysis rates }\end{array}$ & $\begin{array}{l}\text { SSA } \\
\text { value }\end{array}$ \\
\hline REF & No & Yes & 0.95 \\
FE & Yes & Yes & 0.95 \\
TEST_1 & Yes* & Yes & 0.95 \\
TEST_2 & Yes** & Yes & 0.95 \\
TEST_3 & No & No & 0.95 \\
TEST_4 & Yes & No & 0.95 \\
TEST_5 & Yes & Yes & 0.80 \\
\hline
\end{tabular}

* Wildfire emissions in a small region surrounding Moscow are put to zero, see Sect. 5.3 for details.

** Wildfire emissions are estimated without accounting for a possible attenuation of the measured FRP by smoke from fires $(C(\tau)=1$, see Eq. 5$)$.

the Troposphere Ultraviolet and Visible (TUV) model (Madronich et al., 1998). The aerosol impact on photolysis rates, potentially significant in a polluted atmosphere (see e.g. Dickerson et al., 1997; Martin et al., 2003; Hodzic et al., 2007) has not yet been taken into account in the CHIMERE standard version. In this study, we have introduced the TUV (v.5.0) model into the meteorological interface of CHIMERE, and this important modification allowed us to perform off-line calculation of photolysis rates of each model species for each grid cell of the three-dimensional domains of the model as a function of the zenith angle and aerosol optical depth measured by MODIS at $550 \mathrm{~nm}$ (see Sect. 2.1.2). We used a non-uniform wavelength grid for fastTUV calculations of photolysis rates in the troposphere, and an altitude grid with unequally spaced levels with the maximum resolution of $100 \mathrm{~m}$ in the boundary layer.

It is assumed that most aerosol particles are uniformly distributed either within the boundary layer if the boundary layer height is larger than the maximum injection height for smoke aerosols (see below), or up to the maximum injection height otherwise. The calculations are performed with the single scattering albedo (SSA) value equal 0.95 . This value is assumed to be best representative of the range of SSA values $(\sim 0.92-0.97)$ retrieved from AERONET measurements in Moscow during the period a major fire events in summer 2002 (Chubarova et al., 2009) and 2010 (Chubarova et al., 2011). Note that so large SSA values of biomass burning aerosol are not quite typical; for example a much lower value $(\sim 0.8)$ was reported by Meloni et al. (2006) in the case of aerosol originating from forest fires in Western Europe. To test the sensitivity of our results to this parameter, we performed a special model run addressing the case of highly absorbing aerosol (see Sect. 5.3).

Anthropogenic emissions are based on the "expert" annual data of the EMEP emission inventory (UNECE, 2009; EMEP, 2010) taken from the EMEP Centre on Emission In- ventories and Projections (CEIP) website (http://www.ceip. at/) with the initial resolution of $0.5^{\circ} \times 0.5^{\circ}$. For the nested domain, emissions were downscaled proportionally to the population density (GPW, 2010). Higher resolution emission data from other European inventories (e.g. the TNO emission inventory) were tested with CHIMERE but did not yield any better agreement of simulations with monitoring data in Moscow than the downscaled EMEP data.

The estimation of pyrogenic emissions is described in Sect. 4. Here, the choice of the injection height is discussed. In our study, the maximum injection height of fire emissions is defined as a constant parameter. Such a highly simplified approximation of the actual injection height (which in the reality depends on the flaming intensity and meteorological conditions) is partly based on the analysis presented by Sofiev et al. (2009). Specifically, by plotting measured values of the height of real smoke plumes as function of corresponding FRP, they have shown that the plume height was almost independent on FRP within the range of FRP values typical for European fires, and its values are quasi-randomly scattered in the range from about $100 \mathrm{~m}$ to $2 \mathrm{~km}$. Based on these findings, the pyrogenic emissions are homogeneously distributed in the model up to $1 \mathrm{~km}$. It is expected that if the boundary layer height (which is typically less than $2 \mathrm{~km}$ ) exceeds $1 \mathrm{~km}$, then the emissions are rapidly distributed within the boundary layer by turbulent mixing; otherwise, the pyrogenic emissions are expected to be injected above the boundary layer due to pyro-convection. In their own modelling study, Sofiev et al. (2009) used a similar simple approach by assuming that $50 \%$ of the emissions are injected in the lowest $200 \mathrm{~m}$, and the rest is homogenously distributed from $200 \mathrm{~m}$ up to $1 \mathrm{~km}$. Different simple methods were used in other modeling studies addressing effects of fire emissions. For example, Turquety et al. (2007) tested several assumptions for the altitude of injection of North American fire emissions, including injection of all the emissions in the boundary layer, and injection of only $40 \%$ or $60 \%$ of emissions in the boundary layer. They did not find significant differences in comparisons of their simulations with MOPITT measurements over the whole period (three summer months of 2004) considered in their study, although they noted that releasing a significant fraction of emissions in the upper troposphere brought some improvements in simulations downwind from the source regions for the large transport events. In the framework of their inverse modeling study of $\mathrm{CO}$ fire emissions from Alaskan wildfires, Pfister et al. (2005) found that injecting CO only into the boundary layer gave almost the same results as distributing the fire emissions uniformly up to about $7 \mathrm{~km}$.

Two fractions (fine and coarse ones) of aerosol emissions were distributed among 8 size bins with the diameter of particles ranging from $10 \mathrm{~nm}$ to $10 \mu \mathrm{m}$ in accordance to a bi-modal lognormal distribution. The parameters of this distribution were the same as in the study by Hodzic et al. (2007): a fine mode was centered on a $0.25 \mu \mathrm{m}$ mean diameter (1.6 geometric standard deviation) and a coarse mode 
was centered on a $5 \mu \mathrm{m}$ mean diameter (1.4 geometric standard deviation).

During this study, CHIMERE was run for the period from 28 May to 31 August 2010 using several different model configurations. Specifically, a model run was performed with fire emissions and with account for the shielding effects of aerosols, as explained above. This simulation is referred to as the "FE" run and is considered as the base case in this study. To assess the direct effect of fire emissions on the atmospheric composition, the results of the FE run are compared with those of the reference run (which is referred to below as the REF run). The configuration of the REF run is the same as that of the FE run, except that fire emissions are set to be zero. Other model configurations considered in this study are defined in Sect. 5.3. The model runs performed in this work are summarized in Table 1.

\subsection{Initial processing of model results}

The model outputs were processed to insure their consistency with measurements used for their evaluation. To compare simulations of near surface concentrations with the air pollution monitoring data, the hourly concentrations at the lowest model level were first extracted from the model output files for each grid cell whose center is closest to the location of a corresponding monitoring site. Then the hourly concentrations were either averaged over twenty-four hours (for $\mathrm{CO}$ and $\mathrm{PM}_{10}$ ), or the daily maximum concentration was determined (for ozone).

A more complicated processing of model results was needed for their comparison with the MOPITT CO measurements. Specifically, as recommended by Deeter et al. (2009), we took into account the sensitivity of the retrieved $\mathrm{CO}$ vertical profile to the true $\mathrm{CO}$ vertical distribution by means of a logarithmic transformation of the modeled profile:

$\log \left(\boldsymbol{x}_{\mathrm{st}}\right)=\log \left(\boldsymbol{x}_{\mathrm{so}}\right)+\mathbf{A}\left[\log \left(\boldsymbol{x}_{\mathrm{so}}\right)-\log \left(\boldsymbol{x}_{\mathrm{a}}\right)\right]$

where $\boldsymbol{x}_{\mathrm{so}}$ and $\boldsymbol{x}_{\mathrm{st}}$ are the simulated CO profiles before and after the transformation, $\boldsymbol{x}_{\mathrm{a}}$ is the a priori CO profile, and $\mathbf{A}$ is a matrix of the averaging kernels. The transformation Eq. (4) was applied to the simulated CO concentrations in each grid cell and for each hour. Because the exact time of the MOPITT scans (which considerably varies from day to day) is not reported in the MOPITT CO Level 3 (daytime) data product used in this study, the transformed CO concentrations are averaged over the period from sunrise to sunset. We found that the transformed $\mathrm{CO}$ data are quite insensitive to the definition of the averaging period, and that possible biases caused by a probable temporal mismatch between measurements and simulations cannot account for the differences between the measured and simulated $\mathrm{CO}$ mixing ratios discussed in Sect. 5.4.

\section{Estimation of air pollutant emissions from wildfires}

\subsection{Basic formulations}

The fire emission estimates are obtained in this study by assuming a linear relationship between the biomass burning rate and FRP. Such a relationship was identified by Wooster et al. (2005) in measurements of experimental fires. However, taking into account that the experiments could not reproduce a very wide range of real burning conditions, the actual relationship between the wildfire emissions and the FRP data may be much more complex than assumed, and the estimation algorithm described below should be considered as a heuristic procedure.

In this study, the emission rates of gaseous species and particulate matter from wildfires in a given grid cell and at a given hour, $t$, are calculated as follows:

$$
\begin{aligned}
E_{\mathrm{S}}(t) \cong \Phi_{\mathrm{d}} \times \alpha \times\left(\sum_{1}\left[\beta_{\mathrm{sl}} \times \rho_{1}\right] \times F_{1}+\right. \\
\left.\beta_{\mathrm{sp}} \times \rho_{\mathrm{p}} \times F_{2}\right) \times C(\tau) \times p_{\mathrm{h}}(t)
\end{aligned},
$$

where $E_{\mathrm{S}}\left(\mathrm{g} \mathrm{s}^{-1} \mathrm{~m}^{-2}\right)$ is the emission rate of a model species $s, \Phi_{\mathrm{d}}\left(\mathrm{W} \mathrm{m}^{-2}\right)$ is the FRP density (or, in other words, the flux of infrared radiation) derived from satellite measurements (see Eqs. 2 and 3), $\alpha$ (g [biomass] $\mathrm{s}^{-1} \mathrm{~W}^{-1}$ ) is the empirical coefficient transforming the FRP density into the combustion rate density, $\beta_{\mathrm{sl}}$ and $\beta_{\mathrm{sp}}(\mathrm{g}$ [model species])/g [biomass]) are the emission factors for a given land cover type $l$ and peat fires, respectively, $\rho_{1}$ and $\rho_{\mathrm{p}}$ are fractions of land cover type "l" and peatland area in a given grid cell. $F_{1,2}$ are scaling factors optimized in model runs, $p_{\mathrm{h}}$ is the assumed diurnal profile of emissions (see Fig. 1), and $C$ is an additional correction factor (see below) specified as a function of the aerosol optical thickness, $\tau$.

We consider nine different land cover types defined in the CHIMERE CTM used in this study. The fractions of land cover per grid cell are evaluated using Global Land Cover Facility (GLCF) data base (http://www.landcover.org). The land cover types used in CHIMERE and their correspondence to the GLCF data is described in the CHIMERE CTM documentation available on the web (http://www.lmd. polytechnique.fr/chimere/). Additionally, we consider the "peatland" category of the land type by introducing a fraction $\left(\rho_{\mathrm{p}}\right)$ of the land surface identified as the peatland. This approach allows us to take into account, in an indirect way, emissions from peat fires. Although peat fires cannot be directly detected from satellites, we expect that if a crown or surface fire is observed over the dry peatland, there is some probability that a subsurface peat fire takes place at the same time. Note that a similar assumption was made by Turquety et al. (2007) in their modelling study of impacts of peat fires on carbon monoxide pollution of atmosphere over the USA. The peatland map for Russia on the grid of $0.9^{\circ} \times 0.72^{\circ}$ was obtained from the GIS "Peatlands of Russia" (Vompersky et al., 2005) (see Fig. 3). The coarse resolution of this map 


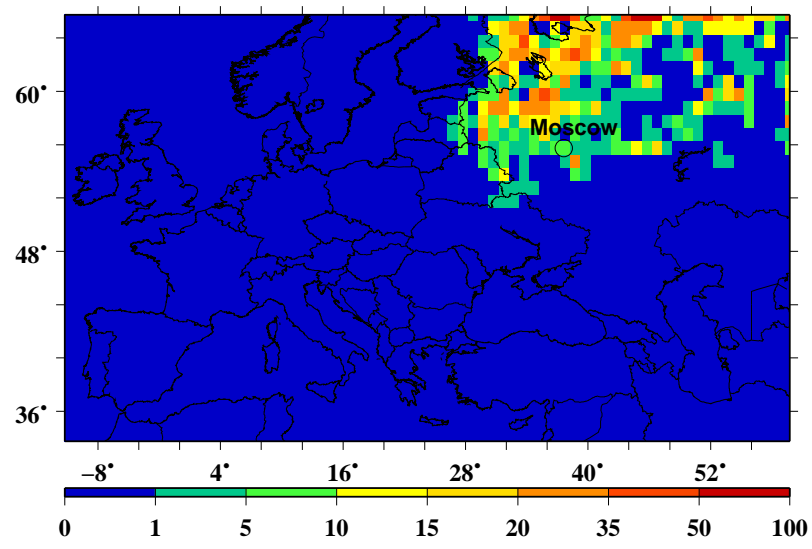

Fig. 3. Fractions (in \%) of peat land in a grid cell. Note that the peat land data used in this study are not representative of any country except Russia.

probably introduces additional uncertainties in emission estimates from peatfires, but taking into account that the assumed relation between FRP and the intensity of peatfires has a probabilistic character it is not at all obvious that further increase of the peatland map's resolution would lead to significantly better emission estimates.

A value of $\alpha\left(3.68 \times 10^{-4} \mathrm{~g} \mathrm{~J}^{-1}\right)$ has been adopted from the experimental study by Wooster et al. (2005). Emission factors for $\mathrm{PM}_{2.5}, \mathrm{PM}_{10}, \mathrm{CO}, \mathrm{NO}_{\mathrm{x}}, \mathrm{SO}_{2}$, and $\mathrm{NH}_{3}$ for different GLCF landuse types were adopted from Wiedinmyer et al. (2006). The total emissions of non-methane hydrocarbons (NMHCs) are evaluated by using the NMHCs emission factor given by Wiedinmyer et al. (2006), while emission factors for individual hydrocarbons (Urbanski et al., 2009) are used to split total NMHCs into emissions of different model species.

In the case of peatland fires, the emission factors for $\mathrm{CO}$, $\mathrm{NO}_{\mathrm{x}}$, and $\mathrm{NH}_{3}$ are assigned using data of laboratory measurements (Yokelson et al., 1997; Christian et al., 2003) combined by Akagi et al. (2011). The emission factors evaluated by Akagi et al. (2011) for several hydrocarbons emitted from peat burning and grassland fires are used to obtain the NMHC emission factor for peat fires by scaling the corresponding factor reported by Wiedinmyer et al. (2006) for grassland. Due to the lack of direct measurements of $\mathrm{PM}_{2.5}$ and $\mathrm{PM}_{10}$ emissions from peat burning, the emission factors for $\mathrm{PM}_{2.5}$ and $\mathrm{PM}_{10}$ are assigned to be the same as for the grasslands, although probably they are much larger (Iinuma et al., 2007). Note that the results of this study are not sensitive to our choices made for emission factors for particulate matter and $\mathrm{CO}$ because the pyrogenic emissions of these species are optimized using measurements (see Sect. 4.2). In contrast, the NMHCs emission estimates are not optimized in this study (but scaling for $\mathrm{CO}$ emission factor is used), and so their accuracy can only be indirectly assessed by comparing simulated ozone concentrations with measurements. Taking into account that the emission efficiency of actual fires may strongly depend on burning conditions (e.g. Muraleedharan et al., 2000), which are not controlled in this study, values of emission factors assigned here (see Table 2) should only be considered as rough estimates. Potential uncertainties in the emission factors can manifest as discrepancies between their estimations in different studies. In this way, Akagi et al. (2011, Table S2) estimated, in particular, that the uncertainty of the $\mathrm{CO}$ emission factor for boreal forest reaches 35 percent; even larger uncertainties (exceeding 50 percent) were reported in the emission factors for several hydrocarbons.

Along with the scaling parameters $F_{1}$ and $F_{2}$, our formulation for wildfire emissions (see Eq. 5) contains one more correction factor, $C$, which is assumed to depend on the aerosol optical thickness, $\tau$. This is an ad hoc parameter introduced in order to account for possible underestimation of FRP from fires obscured by smoke aerosols. Heavy smoke is mentioned by Giglio (2010) among the main factors affecting accuracy of MODIS fire data products. Based on the limited number of numerical experiments, it was found that the agreement of model simulations with measurements drastically improves if $C(\tau)$ is defined as follows:

$C(\tau)=\exp \left(\kappa \mathrm{AOD}_{\text {modis }}\right)$

where $\mathrm{AOD}_{\text {modis }}$ is the aerosol optical depth at $550 \mathrm{~nm}$, obtained with $1 \times 1^{\circ}$ resolution as a MODIS Level 3 data product provided from MODIS measurements (see Sect. 2.1.2) and $\kappa$ is a constant which, in our simulations, was set to be unity. A methodical optimization of $\kappa$ was not carried out. However, it was found that setting $\kappa$ values to much smaller or larger than unity degrades model performance. Therefore, $\kappa$ was set to 1 in this study, and the sensitivity to this parameter is examined in Sect. 5.3.

The idea behind the relation given by Eq. (6) is rather simple. As it is shown by Wooster et al. (2003, 2005), FRP derived from MODIS measurements using Eq. (1) can alternatively be expressed as a linear function of the spectral radiance, $L_{\mathrm{f}}$, emitted in the 3.4-4.2 $\mu \mathrm{m}$ wavelength range. The measured spectral radiance, $L_{\mathrm{f} \text {,meas }}$, is attenuated by aerosols, such that

$L_{\mathrm{f} \text {,meas }} \approx L_{\mathrm{f} \text {,true }} \exp \left(-\tau_{4}\right)$,

where $L_{\mathrm{f}, \text { true }}$ and $\tau_{4}$ are the true spectral radiance and aerosol optical thickness at the $4 \mu \mathrm{m}$ wavelength, respectively. The measured FRP should be attenuated in a similar way. Since the measurements of $\tau_{4}$ have not been available, we used $\mathrm{AOD}_{\text {modis }}$ at $550 \mathrm{~nm}$ (with $1 \times 1^{\circ}$ resolution) as a substitute. Relating $\mathrm{AOD}_{\text {modis }}$ and $\tau_{4}$ is not easy, because not only optical properties of aerosols but also the spatial structure of $\tau_{4}$ on fine scales which are not captured by $\mathrm{AOD}_{\text {modis }}$ data should be taken into account. For example, heavy smoke over an isolated single fire could completely obscure it from a satellite sensor, but, at the same time, the corresponding 
Table 2. Biomass burning emission factors $\left(\mathrm{g} \mathrm{kg}^{-1}\right)$ specified in the fire emission model (see Eq. 5) for different types of land. Note that the emission factors for four other surface types (bare land, inland water, ocean, and urban) considered in CHIMERE are set to be zero.

\begin{tabular}{lcrrrrr}
\hline & agricultural & grass & shrubs & $\begin{array}{r}\text { needleleaf } \\
\text { forest }\end{array}$ & $\begin{array}{r}\text { broadleaf } \\
\text { forest }\end{array}$ & peatland \\
\hline $\mathrm{CO}$ & 70 & 90 & 84 & 8.9 & 94 & 210 \\
$\mathrm{NO}_{\mathrm{x}}$ (as NO) & 2.4 & 6.5 & 3.2 & 2.5 & 2.1 & 1.0 \\
$\mathrm{NMHC}_{\mathrm{SO}}$ & 6.7 & 5.0 & 3.2 & 6.3 & 6.8 & 24.3 \\
$\mathrm{NH}_{3}$ & 0.4 & 0.5 & 0.5 & 0.8 & 0.8 & 0.5 \\
$\mathrm{PM}_{2.5}$ & 1.5 & 0.6 & 0.6 & 0.9 & 0.6 & 14.3 \\
$\mathrm{PM}_{10}$ & 5.7 & 9.5 & 5.6 & 11.7 & 11.2 & 9.5 \\
\hline
\end{tabular}

$\mathrm{AOD}_{\text {modis }}$ value (representing a much larger territory) would not be significantly different from a background value. If the area affected by the fires within a $1 \times 1^{\circ}$ grid cell (with the total area of about $5000 \mathrm{~km}^{2}$ in the considered Russian region) in the MODIS AOD data product is, e.g. only about $500 \mathrm{~km}^{2}$, the actual optical depth over these fires may be about a factor of ten larger than the corresponding spatially averaged values of $\mathrm{AOD}_{\text {modis. }}$ On the contrary, available estimations using Mie theory (Key, 2001) suggest that $\tau_{4}$ is much smaller than AOD at $550 \mathrm{~nm}$ for a given air column. As a conclusion, a more detailed analysis of possible impacts of aerosols on FRP measurements is very difficult and goes beyond the scope of this paper.

\subsection{Optimization procedure}

Basically, the idea of the optimization procedure performed in the framework of this study is to find estimates of certain parameters of a model which provide the best agreement of simulations with measurements. Note that this idea is akin to the general ideas behind both the inverse modeling (e.g. Enting, 2002) and data assimilation (Eskes et al., 1999; Elbern et al., 2007; Barbu et al., 2009) approaches. In this study, we attempt optimization of a parameter vector, $\boldsymbol{F}$, which consists of only two components which are the scaling factors $F_{1}$ and $F_{2}$ (see Eq. 5). As a result, we not only optimize the model performance but also obtain emission estimates that are consistent with available measurements. It should be kept in mind, however, that these estimates are sufficiently accurate only if the modeled relationship between concentrations and emissions is correct, subject to some random uncertainties in model results. This is a common condition assumed in any inverse modeling study. On the other hand, the improvement of model performance resulting from parameter optimization can be considered as a self-sufficient goal, irrespectively of the physical meaning attributed to the optimized parameters. This goal is typical for data assimilation studies.

Our optimization algorithm is based on the "twin experiment" method. Specifically, we first performed the model run with both $F_{1}$ and $F_{2}$ equal to unity $\left(F_{1}=F_{2}=1\right)$. The next two runs were successively performed with $F_{1}$ value increased by $10 \%$ and with a similarly perturbed value of $F_{2}$. The results of all these runs were used to estimate partial derivatives of $\mathrm{CO}$ and $\mathrm{PM}_{10}$ concentrations with respect of $F_{1}$ and $F_{2}$. Under the assumption (which is justified below) that the relationships between $\mathrm{CO}$ and $\mathrm{PM}_{10}$ concentrations and corresponding fire emissions are linear, the estimates of these derivatives allowed us to find the optimal parameter values, $\boldsymbol{F}_{\text {opt }}$, providing a minimum of a cost function, $J$, which is defined as a mean square error (MSE) of the model:

$$
\begin{aligned}
\boldsymbol{F}_{\mathrm{opt}} & =\arg \min (J) ; \\
J & =\frac{1}{N} \sum_{i=1}^{N}\left(C_{\mathrm{m}}^{i}-C_{\mathrm{o}}^{i}-\Delta_{\varepsilon}\right)^{2},
\end{aligned}
$$

where $\boldsymbol{C}_{\mathrm{m}}$ and $\boldsymbol{C}_{\mathrm{o}}$ are the modeled and observed daily mean concentrations, respectively, $i$ is the index of a day, $N$ is the total number of days provided with observations, and $\Delta_{\varepsilon}$ is a bias (systematic error) of the simulations. The bias is assumed to be independent of any processes caused by wildfire emissions and is estimated as a difference between the simulated and observed concentrations averaged over the period from 1 June to 15 July 2010. According to our simulations (see Sect. 5.2), the impact of wildfires on air pollution in Moscow during this period was indeed quite negligible. Technically, $\boldsymbol{F}_{\text {opt }}$ was found by resolving a system of two linear algebraic equations obtained by requiring that the partial derivatives of $J$ with respect to $F_{1}$ and $F_{2}$ are equal zero. Different sets of optimal parameters were obtained for $\mathrm{CO}$ and particulate matter (PM), with the same correction factor applied to both fine and coarse fractions of aerosol. The efficiency of our simple optimization procedure is directly manifested in results of comparison of optimized simulated concentrations with observations (see Sect. 5.2).

The optimization procedure employed in this study is relatively simple because not only any nonlinearities in relationships between concentrations of $\mathrm{CO}$ and $\mathrm{PM}_{10}$ and their emissions from wildfires turned out to be small, but also the interaction between these species is rather negligible. In principle, changes in $\mathrm{CO}$ emissions can affect $\mathrm{PM}_{10}$ 
concentrations through changes in chemical processes driving formation of secondary aerosols. However, in the considered situation with intensive wildfires, the fraction of secondary aerosol compounds in the simulated $\mathrm{PM}_{10}$ concentration turned out to be small (as noted in Sect. 5.2). Aerosol emissions can, in principle, affect $\mathrm{CO}$ concentration by modulating photolysis rates of many gaseous species which directly or indirectly interact with $\mathrm{CO}$. However, the simulated aerosols concentrations were not used in this study for evaluation of radiative effects of aerosols. Instead, these effects were taken into account by using satellite AOD measurements, as described in Sect. 3.1. The legitimacy of a linear approximation for the relationships between $\mathrm{CO}$ (or $\mathrm{PM}_{10}$ ) concentrations and corresponding wildfire emissions is confirmed by results of a comparison of $\mathrm{CO}$ and $\mathrm{PM}_{10}$ concentrations estimated using a linear relationship between them and the wildfire emission factors and those simulated by CHIMERE with $\boldsymbol{F}=\boldsymbol{F}_{\text {opt }}$ (see Fig. 4). The efficiency of our simple optimization procedure is also directly manifested in results of comparison of optimized simulated concentrations with observations (see Sect. 5.2).

Optimized values of the factors $F_{1}$ and $F_{2}$ in the cases of $\mathrm{CO}$ and $\mathrm{PM}$ emissions are not directly applicable for the estimation of emissions of other model species, such as $\mathrm{NO}_{\mathrm{x}}$ and NMHCs. If the emission factors $\beta_{\mathrm{s}}$ were known exactly, the optimal values of $F_{1}$ and $F_{2}$ would be the same for all species. Unfortunately, as it is demonstrated below, our optimization procedure yields rather different values in the cases of $\mathrm{CO}$ and PM, and this means that actual values of emission factors for different species in the considered fires might be significantly different from those assumed in our algorithm. In this situation, we have estimated emissions of all model gas species simply using the set of values of $F_{1}$ and $F_{2}$ obtained in this study for CO (see Sect. 5.1).

\subsection{Potential uncertainties in emission estimates}

While the accuracy of simulated concentrations of the considered species can be evaluated through their direct comparison to corresponding measurements, estimation of uncertainties in emission estimates derived from the measurements with an inverse modeling method is a quite challenging task, which so far does not have a universal solution in a common case (see e.g. Enting, 2002). In the considered complex situation, there are many error components (e.g. measurement errors, representativity errors caused by a limited spatial resolution of the model, errors in anthropogenic and natural emissions, uncertainties associated with chemical mechanism and parameterization of aerosol processes, errors in boundary conditions, etc.). Each of these components may satisfy a different unknown probability distribution, and its contribution to differences between measurement and simulations may vary in both time and space. Accordingly, only very rough estimates of uncertainties in our results can be obtained without a detailed knowledge of all these factors. In
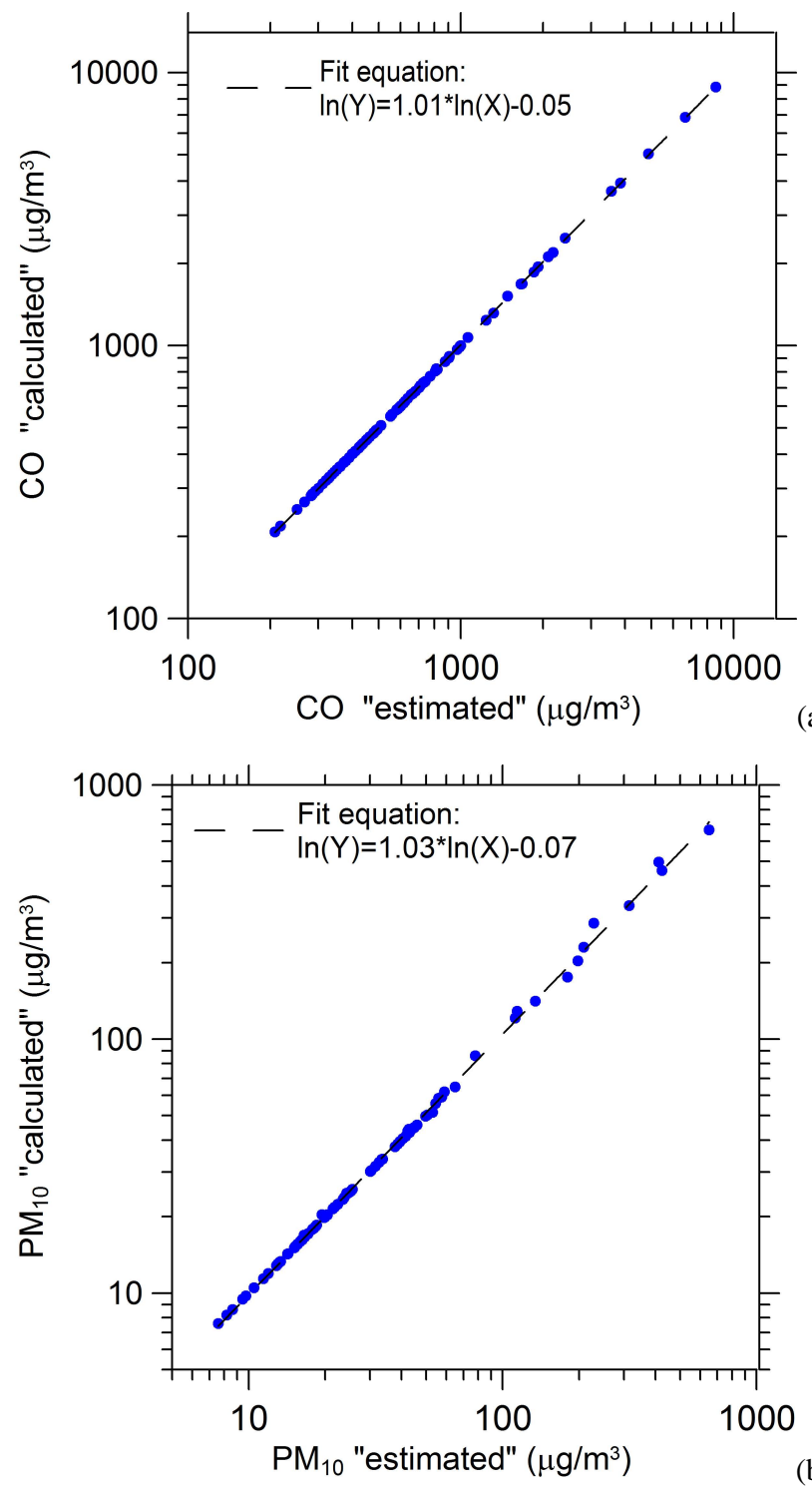

(a)

Fig. 4. $\mathrm{CO}$ (a) and $\mathrm{PM}_{10}$ (b) daily mean concentrations estimated using a linear relationship between them and the wildfire emission factors $(F)$ in comparison with corresponding concentrations calculated directly by CHIMERE. Both the "estimated" and "calculated" concentrations are obtained with optimal values of the correction factors $F$ (see Sect. 5.1 and Table 3). The "estimated" concentrations are obtained by applying a linear correction to concentrations simulated with $F_{1,2}=1$. The data are presented for the period from 1 June to 30 August 2010.

this section we first describe a simple method which is used to roughly estimate the range of "intrinsic" uncertainties in our fire emissions estimates, which are associated with the inverse modeling procedure. Then we discuss several major factors which can contribute to additional biases in our estimates but cannot be evaluated in a formal way.

The intrinsic uncertainties in our estimates of the spatially and temporally averaged fire emissions can be expressed as 
Table 3. Optimal estimates of the correction factors $F_{1}$ and $F_{2}$ (see Eq. 5). The uncertainties reported in brackets are evaluated as the geometric standard deviation corresponding to the 68.3 th percentile of the probability distributions of logarithms of the correction factors obtained in a Monte Carlo experiment.

\begin{tabular}{lcc}
\hline & $F_{1}$ & $F_{2}$ \\
\hline CO & $0.24(1.52)$ & $1.68(1.72)$ \\
PM & $0.13(1.21)$ & $1.30(1.67)$ \\
\hline
\end{tabular}

uncertainties in the optimized values of the factors $F_{1}$ and $F_{2}$. We expect that a major part of the uncertainties in $F_{1}$ and $F_{2}$ is manifested as "random" differences between simulated and measured concentrations. Specifically, this part of uncertainties is determined by differences between simulation and observations, which vary from day to day. These are uncertainties associated with an inverse modeling procedure in a situation when neither measurements nor a model are perfect. To obtain rough estimates of such kind of uncertainties in $\boldsymbol{F}_{\text {opt }}$, we performed a Monte Carlo experiment (see e.g. Press et al., 1992). For this experiment, values of CO and $\mathrm{PM}_{10}$ concentrations simulated with the optimal parameter values were considered as a substitute for the true values of these concentrations. Following a common approach used in inverse modeling studies (e.g. Tarantola, 1987), we do not discriminate between uncertainties in measurements and simulations but rather characterize all of them by introducing an effective observational error satisfying (in our case) a Gaussian probability distribution. The standard deviation, $\sigma_{\varepsilon}$, of this probability distribution is evaluated as the root mean square deviation of the "true" concentrations from corresponding observations in the period of intensive wildfires in the Moscow region (from 20 July to 20 August). Choices of the type of probability distribution and of the period used to evaluate $\sigma_{\varepsilon}$ are made in an attempt to best characterize actual uncertainties but they are nevertheless subjective. The errors sampled from the Gaussian distribution with the standard deviation $\sigma_{\varepsilon}$ were applied to the substitutes of the true concentrations, and the estimation procedure defined by Eq. (8) was repeated with the randomly perturbed concentrations serving as substitutes for $C_{\mathrm{m}}$. The sampling of random errors and the evaluation procedure were re-iterated 1000 times to obtain the statistical distributions of logarithms of $F_{1}$ and $F_{2}$. Finally, the geometric standard deviation corresponding to the 68.3 percentile of these distributions is calculated as a quantitative indicator of uncertainties in $\boldsymbol{F}_{\text {opt }}$.

As noted above, our estimates may be subject to additional biases which cannot be formally evaluated in the framework of our study and should be considered together with the intrinsic uncertainties. A basic assumption which is used in this study to calculate two-dimensional hourly fields of wildfire emissions (see Eq. 5) is direct proportionality of the emission rates to FRP measured from satellites. This assumption is supported by convincing experimental evidences (Wooster et al., 2005). As it is mentioned above (see Sect. 4.1), the relationship between the emissions and FRP in the real atmosphere can be affected, in particular, by heavy smoke from fires. To take into account the effect of smoke, we introduced a special correction factor $(C)$ which is specified in a rather crude way as an exponential function of AOD retrieved from the MODIS measurements at $550 \mathrm{~nm}$ (see Eq. 6). It is possible that some uncertainties in our emission estimates are associated with the evaluation of this factor. Although the magnitude of these uncertainties is difficult to evaluate due to lack of knowledge about the spatial distribution and optical properties of the considered smoke aerosol in the infrared region, we expect that at least their systematic part can be strongly reduced as a result of the optimization procedure described in the previous section. It should be kept in mind, however, that monitoring data used in this study allow us to constrain emissions (by optimizing values of $F_{1}$ and $F_{2}$ ) only in a rather close vicinity of Moscow (a typical distance from fires strongly affecting air quality in Moscow does not exceed $200 \mathrm{~km}$, as evidenced by the results presented in Sect. 5.3). Emission estimates reported in the next section for larger regions are obtained assuming that the same optimal values of $F_{1}$ and $F_{2}$ are applicable to more distant fires. This assumption cannot be validated, although it is, to some extent, corroborated by the fact that, according to our results (see Sect. 5.1), major fire emissions in European Russia occurred in a rather compact region featuring similar vegetative cover (mixed and coniferous forests).

It is also assumed in Eq. (5) that subsurface peat fires occur at the same time and place as a crown or surface fire visible from space (as a matter of evidence, only in the fraction of grid cells covered by peatlands). This is a rough assumption which may not be always valid, but it is useful because it allows us to estimate emissions from peat fires separately from emissions from other fires. The uncertainties associated with possible deviations from the assumed relationship between FRP and emissions from peatlands may be very large for individual grid cells, but by separately optimising the factor $F_{2}$ we try to insure that our estimates of the spatially and temporally averaged emissions are reasonably accurate. The uncertainty in the optimised value of $F_{2}$ is estimated as discussed in this section above. We do not expect that this value may exhibit a considerable additional bias, although it again should be kept in mind that the emissions from peat fires are constrained in this study only by measurements in the Moscow region.

The injection height of air pollutant emissions is one more factor which can affect our estimates of fire emissions. As it is explained in Sect. 4.3, our choice of the injection height (in our simulations, the pyrogenic emissions are homogeneously distributed in the model up to $1 \mathrm{~km}$ ) is based on the smoke plume height analysis presented by Sofiev et al. (2009). In principle, if a considerable part of fire emissions were injected (in the real atmosphere) much higher than the typical 
boundary layer height in the considered region during daytime $(1.5-2 \mathrm{~km})$, our analysis could yield underestimated emission values (because a higher injection height would lead to smaller air pollutant concentrations at the monitoring sites). However, taking into account the analysis by Sofiev et al. (2009), it seems unlikely that the fraction of emissions injected directly in the free troposphere was actually significant. As mentioned in Sect. 3.1, numerical experiments performed in other modeling studies addressing effects of fire emissions (Pfister et al., 2005; Turquety et al., 2007) did not reveal strong sensitivity of the modelled $\mathrm{CO}$ concentration to the injection height. A possible bias associated with this factor in our emission estimates is difficult to evaluate; our subjective estimate based on the mentioned above facts is that it is not likely to exceed 30 percent (but probably it is much smaller).

The results shown in Fig. 4 (see Sect. 4.2) indicate that the impact of chemical processes on concentrations of $\mathrm{CO}$ and $\mathrm{PM}_{10}$ in the Moscow region during the considered period is very small. Indeed, the first guesses for $\mathrm{CO}, \mathrm{PM}_{10}$, and VOC fire emissions specified in the optimization procedure (with $\left.F_{1}=F_{2}=1\right)$ were several times larger than the optimized emissions (see Sect. 5.1). Still, the $\mathrm{CO}$ and $\mathrm{PM}_{10}$ concentrations corresponding to optimal emissions could be accurately evaluated simply by linear scaling of the concentrations obtained with $F_{1}=F_{2}=1$. This would not be possible if, for example, strong changes in $\mathrm{OH}$ concentration, caused by changes in the emissions, had a strong impact on $\mathrm{CO}$ concentration. Therefore, we believe that any possible inaccuracies in the chemical mechanism of the model are not among major factors contributing to uncertainties in our emission estimates. There could be, however, errors associated with possible inaccuracies of description of transport processes in the model. For example, specific urban effects, such as urban roughness and anthropogenic heat fluxes (see e.g. Baklanov et al., 2009) may be not negligible in the considered megacity region, but they are not taken into account in our simulations. Available experimental studies of the impact of urban canopy and anthropogenic heat fluxes on the boundary layer over Moscow (e.g. Kadygrov et al., 2002; Khaikine et al., 2006) suggest that the boundary layer height in summer may be up to 30 percent larger in the city than outside, although typically the difference is probably much smaller. This effect can cause a corresponding negative bias in our emission estimates. Nonetheless, the fact (as it is shown in Sect. 5.2) that the model reproduces the daily variability of measured concentrations of several species $\left(\mathrm{CO}, \mathrm{PM}_{10}\right.$ and $\mathrm{O}_{3}$ ) rather adequately indicates that, on the whole, the model is reasonably accurate.

As a conclusion, any systematic biases (in addition to intrinsic uncertainties associated with our inverse modeling procedure) in the wildfire emission estimates reported in Sect. 5.1 are not likely to exceed several tenths of percent. We would like to emphasize that we do not consider these estimates as a major result of this study. Rather, we regard them as a potentially useful "byproduct" of our analysis. The corresponding results should be considered together with limitations and uncertainties discussed above. These uncertainties and limitations cannot invalidate any of the results presented in Sects. 5.2 and 5.3.

\section{Results}

\subsection{Wildfire emissions in summer 2010}

The optimal estimates of the correction factors $F_{1}$ and $F_{2}$ (see Eqs. 5 and 8) are reported in Table 3. Although these factors do not have any definite physical meaning, their optimized values and uncertainties can give some idea about possible inaccuracies in other parameters involved in the relationship between FRP and wildfire emissions as well as about the relative importance of emissions from peat fires. In particular, the fact that the optimal values of both $F_{1}$ and $F_{2}$ are significantly larger in the case of $\mathrm{CO}$ than in the case of $\mathrm{PM}$ shows that either the emission factors for $\mathrm{CO}$ were considerably underestimated (relative to the emission factors for PM) or emission factors for PM were overestimated (relative to the emission factors for $\mathrm{CO}$ ). The fact that $F_{2}$ is found to be much larger than $F_{1}$ indicates that the emission efficiency of detected fires in peat lands is many times larger than that in the case of fires occurring above ground. This is an expected result because peat fires normally cannot be detected from space, and a small overground fire seen from a satellite may be associated with strong emissions from subsurface smoldering fires. The interpretation of magnitudes of the correction factors is difficult because they may reflect uncertainties not only in the physical parameters of our algorithm but also in the input FRP data and in the assumed diurnal profile of fire emissions as well. In particular, the use of FRP maxima detected during the course of a day to characterize the daily mean FRP values may lead to systematic overestimation of daily mean FRP estimates (and $F_{1}$ and/or $F_{2}$ values below unity) if the measured FRP data are noisy or variable. It is recalled that maximum values were used because average values risked to be contaminated by clouds. Too small values of the diurnal profile $\left(p_{\mathrm{h}}(t)\right)$ of wildfire emissions at nighttime can also cause overestimation of daily mean FRP values. A special test has shown that if the assumed diurnal profile of fire emissions were uniform, values of $F_{1}$ and $F_{2}$ would be up to a factor of four larger. Note that uncertainties in our estimates of the correction factors not only depend on model and observations errors but also on the amount of available information allowing to resolve effects from peat fires and overground fires. Not surprisingly, the uncertainties are larger in $F_{2}$ than in $F_{1}$ estimates.

The ratio of the emission rate $\left(E_{\mathrm{S}}\right.$, see Eq. 5) to FRP $\left(\Phi_{\mathrm{d}}\right)$ determines the emission coefficient characterizing the amount (in grams) of the species $s$ emitted per joule of the radiated energy. In our case, a value of this coefficient may 
strongly vary in space and time since it involves the correction factor $C$ depending on the aerosol optical depth. In the case of $\mathrm{PM}_{10}$, the value of the emission coefficient averaged over the smaller (nested) domain covering the Central European Russia (CER) in the period of intensive fires from 20 July to 20 August is found to be about $3 \times 10^{-6} \mathrm{~g} \mathrm{~J}^{-1}$. This value is more than an order of magnitude smaller than a range of values $\left(8-10\left(\times 10^{-5}\right) \mathrm{g} \mathrm{J}^{-1}\right)$ of the aerosol emission coefficient estimated by Ichoku and Kaufman (2005) for fires in Western Russia. It is also much smaller than values (1.8-3.5 $\left.\left(\times 10^{-5}\right) \mathrm{g} \mathrm{J}^{-1}\right)$ adopted by Sofiev et al. (2009). However, our estimate is not very different from the emission coefficient value $\left(\sim 5.5 \times 10^{-6} \mathrm{~g} \mathrm{~J}^{-1}\right)$ which can be obtained as the product of the fuel combustion coefficient $\left(3.68 \times 10^{-4} \mathrm{~g} \mathrm{~J}^{-1}\right)$ reported by Woooster et al. (2005) and the $\mathrm{PM}_{10}$ emission coefficient for temperate forests $\left(15 \mathrm{~g} \mathrm{~kg}^{-1}\right)$ recommended by Wiedinmyer et al. (2006). The differences between all these estimates may reflect a yet limited knowledge about potential biases in the MODIS FRP data, as well as the differences in initial FRP data processing. In particular, the maximum daily FRP values modified with the assumed diurnal profile were used in our study, while Ichoku and Kaufman (2005) considered the average of all fire pixels falling into each aerosol pixel. A number of tests carried out in a preliminary stage of this study indicated that differences in the MODIS FRP data preprocessing may indeed account for the mentioned differences in the emission coefficient estimates.

The estimates of wildfire emissions obtained using Eq. (5) with the optimized values of $F_{1}$ and $F_{2}$ are presented in Fig. 5 which shows spatial distributions of monthly mean $\mathrm{CO}$ fluxes from wildfires in comparison with seasonally averaged distributions of anthropogenic $\mathrm{CO}$ fluxes. The distributions are shown separately for the large European domain of CHIMERE and for the smaller (nested) domain covering only the Central European Russia (CER). It can be seen that while wildfire emissions in June were quite negligible with respect to anthropogenic emissions, they were very considerable in August. According to our estimates, wildfire emissions were strongest in the CER region, that is, not far from Moscow. Importantly, $\mathrm{CO}$ fluxes in certain regions (e.g. near Ryazan) were much larger than anthropogenic $\mathrm{CO}$ emissions from Moscow.

The estimates of total amounts of carbon monoxide emitted in different regions and months are listed in Table 4. Note that we cannot claim that our estimates concerning the European part of Russia or the whole Europe are sufficiently constrained by measurements, because measurements in Moscow are mainly sensitive to emissions in the CER region. Taking into account that actual uncertainties in our total emission estimates are not sufficiently known (see Sect. 4.3), the uncertainty ranges are thus not reported here. Nonetheless, recognizing all possible uncertainties, we believe that our independent estimates are sufficiently adequate, and they can be useful for characterizing the global and regional impacts of 2010 Russian wildfires.
According to our estimates, the CER region provided the major part of total pyrogenic emission in Europe in $\mathrm{Au}-$ gust 2010. Moreover, only about $9 \%$ of the total European amount of pyrogenic CO were emitted outside of Russia (mainly, in Portugal). Magnitudes of emissions are quite impressive: specifically, the total pyrogenic $\mathrm{CO}$ emissions in the European region of Russia (9.7 Tg) in summer 2010 constitute more than $85 \%$ of the total annual anthropogenic CO emissions in the same region $(\sim 11 \mathrm{Tg}$ according to CEIP, http://www.ceip.at/emission-data-webdab). About 30 percent of total CO fire emissions in Russia are identified by our model optimization procedure as emissions from peat fires.

For comparison, we calculated $\mathrm{CO}$ emissions for the selected regions using the gridded (with the 0.5 by 0.5 degree resolution) monthly data of the Global Fire Emissions Database version 3 (GFED3) (van der Werf et al., 2010; http://www.globalfiredata.org). The corresponding values are also given in Table 4. Unfortunately, contribution of peatfires to the total $\mathrm{CO}$ fire emissions in Russia was not provided in the available GFED3 data. Similar to our estimates, GFED3 shows that the intensity of fire emissions strongly increased in Western Russia from June to August. However, our estimates are, on the average, about a factor of three larger than the values obtained from GFED3. The reasons for these large differences are not known; we cannot explain them by any inaccuracies in our approach. Note that the country-level estimates are provided in GFED3 with the warning about possible large uncertainties and potential for missing key regional aspects in the global approach used.

An independent estimate of the total $\mathrm{CO}$ amount (between 34 and $40 \mathrm{Tg}$ ) emitted in the region covering almost the whole Russia as a well as parts of Kazakhstan, Mongolia and other neighbouring states during July and August 2010 was reported by Yurganov et al. (2011). Using a simple box model, they performed an inversion of $\mathrm{CO}$ mixing ratios derived from satellite measurements. A direct comparison of their estimate with ours is not meaningful because of a mismatch between the considered regions. Indeed, according to the GFED3 gridded data, the largest part of the total annual CO emitted from fires in Russia in 2010 is attributed to fires in Siberia and Russian Far East. These regions are not covered by our model. However, the estimate by Yurganov et al. can be compared directly to the annual 2010 emissions in Russia, Kazakhstan and Mongolia (20.6 Tg in total), which are reported in the GFED3 tables (//www.falw.vu/ gwerf/ GFED/GFED3/tables/countries/). Thus, differences between both methods are about a factor two, not very different to the factor 3 deviation between GFED3 results and ours in the more restricted European Russian region. 

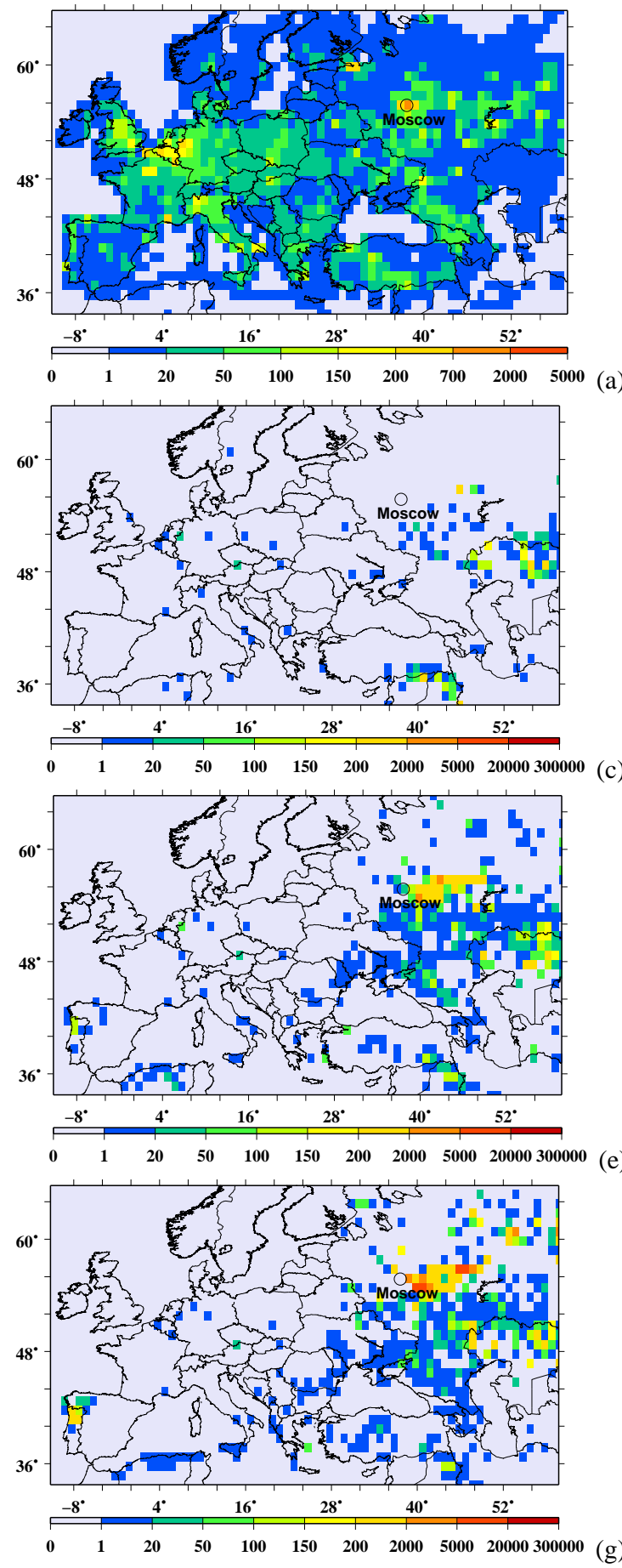
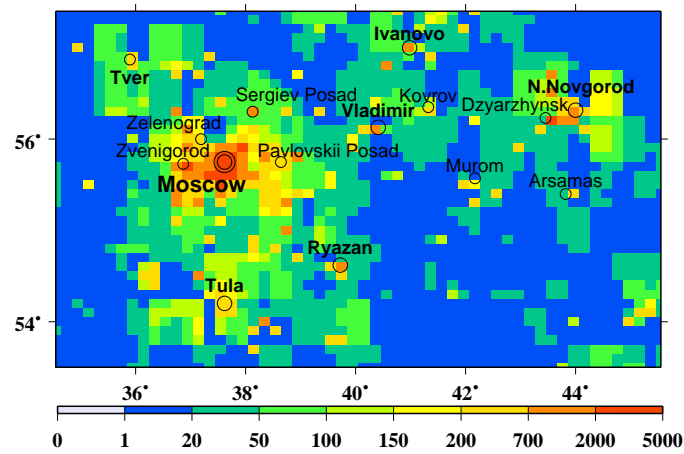

(b)

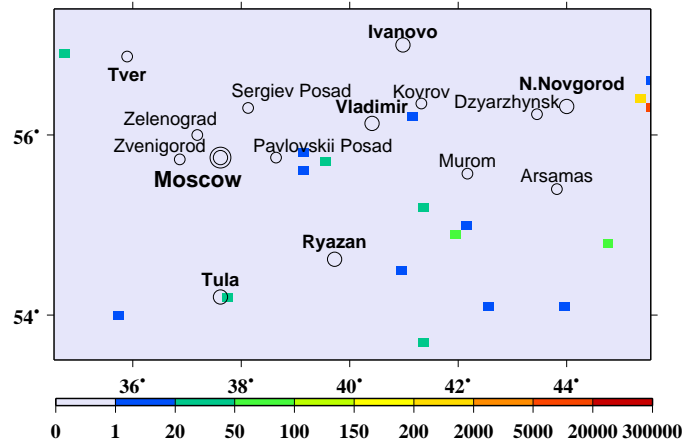

(d)

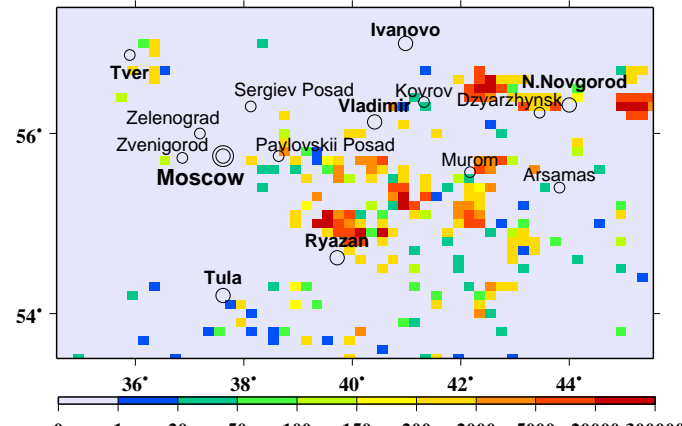

(f)

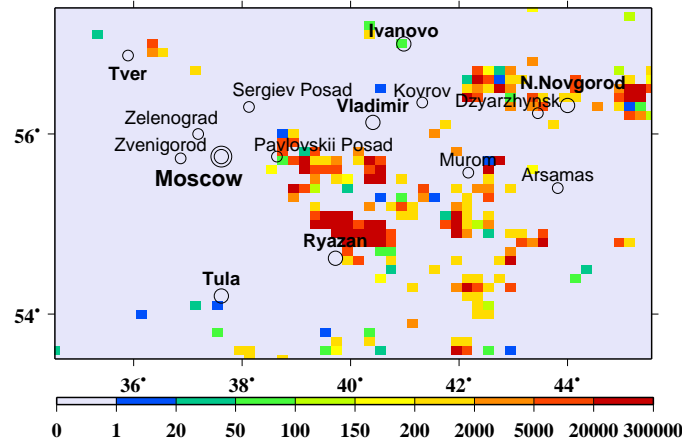

(h)

Fig. 5. Rates of anthropogenic (a, b) and pyrogenic (c-h) CO emissions specified in CHIMERE (in $10^{10}$ molecules ( $\left.\mathrm{cm}^{-2} \mathrm{~s}\right)$ ). Anthropogenic emissions are averaged over three summer months (June-August) and pyrogenic emissions are presented as averages over June (c, d), July (e, f), and August $(\mathbf{g}, \mathbf{h})$. The emission rates are shown separately for a large model domain covering both Western and Eastern Europe with the coarse resolution of $1^{\circ} \times 1^{\circ}$ (on the left) and for a small (nested) domain covering only Central European Russia with the finer resolution of $0.2^{\circ} \times 0.1^{\circ}$ (on the right). Note that the colour palette in the case of pyrogenic emissions is extended. 
Table 4. Estimates of total amounts of CO (Tg) emitted in different regions and months in summer 2010.

\begin{tabular}{lcrrrrrrr}
\hline & & \multicolumn{2}{c}{ June } & \multicolumn{2}{c}{ July } & \multicolumn{2}{c}{ August } \\
\cline { 3 - 8 } & & All fires & Peat fires & All fires & Peat fires & All fires & Peat fires \\
\hline \multirow{2}{*}{ Central European Russia } & this study & $<0.01$ & $<0.01$ & 1.33 & 0.42 & 4.89 & 1.58 \\
& GFED3.1 & $<0.01$ & NA & 0.42 & NA & 0.80 & NA \\
\hline \multirow{2}{*}{ European Russia } & this study & 0.03 & $<0.01$ & 1.83 & 0.57 & 7.85 & 2.60 \\
& GFED3.1 & 0.13 & NA & 1.06 & NA & 1.67 & NA \\
\hline \multirow{2}{*}{ Europe } & this study & 0.14 & $<0.01$ & 2.29 & 0.57 & 8.31 & 2.60 \\
& GFED3.1 & 0.13 & NA & 1.18 & NA & 1.98 & NA \\
\hline
\end{tabular}

\subsection{Comparative analysis of simulated and measured time series of air pollutant concentrations in the Moscow region}

Figures 6-8 present time series of simulated concentrations of $\mathrm{CO}, \mathrm{PM}_{10}$ and $\mathrm{O}_{3}$ in the Moscow region in comparison with corresponding monitoring data. Supplementary meteorological information is presented in Fig. 9. Simulations were performed both with and without fire emissions (see the curves for the FE and REF runs, respectively). Concentrations of primary pollutants used in our optimization procedure are presented separately for the two groups of sites (see Sect. 2.2), one of which is used for optimization of wildfire emissions and another - only for validation of model results. Note that $\mathrm{CO}$ and $\mathrm{PM}_{10}$ concentrations are shown with a logarithmic scale.

The observed $\mathrm{CO}$ and $\mathrm{PM}_{10}$ concentrations exhibited very strong positive perturbations in the period from 3 to $15 \mathrm{Au}-$ gust. The largest $\mathrm{CO}$ and $\mathrm{PM}_{10}$ concentrations were observed in Moscow on 7 August (68th day at the figures). Specifically, average (over all of the monitors considered in this study) concentrations of $\mathrm{CO}$ and $\mathrm{PM}_{10}$ exceeded $10 \mathrm{mg} \mathrm{m}^{-3}$ and $700 \mu \mathrm{g} \mathrm{m}^{-3}$, respectively, while the maximum daily mean concentrations registered at individual monitoring sites in Moscow in that day reached $20 \mathrm{mg} \mathrm{m}^{-3}$ for $\mathrm{CO}$ and $900 \mu \mathrm{g} \mathrm{m}^{-3}$ for $\mathrm{PM}_{10}$. These concentrations significantly exceeded threshold values established by Russian air quality standards (which are $3 \mathrm{mg} \mathrm{m}^{-3}$ and $150 \mu \mathrm{g} \mathrm{m}^{-3}$ for daily mean of $\mathrm{CO}$ and $\mathrm{PM}_{10}$ concentrations, respectively). Very large aerosol concentrations were associated with strongly reduced visibility (see Fig. 10). The observed ozone concentrations were also enhanced in August, but to a lesser extent than primary pollutant concentrations. Interestingly, the peaks of $\mathrm{CO}$ and $\mathrm{PM}_{10}$ concentrations on 7 August were not associated with a similar maximum in ozone. In general, temporal variability in the ozone time series is much larger than that for $\mathrm{CO}$ and $\mathrm{PM}_{10}$.

The formation of the strong air pollution episodes took place in the hot and dry atmosphere inside of a blocking anticyclone accumulating tropical air transported to West-
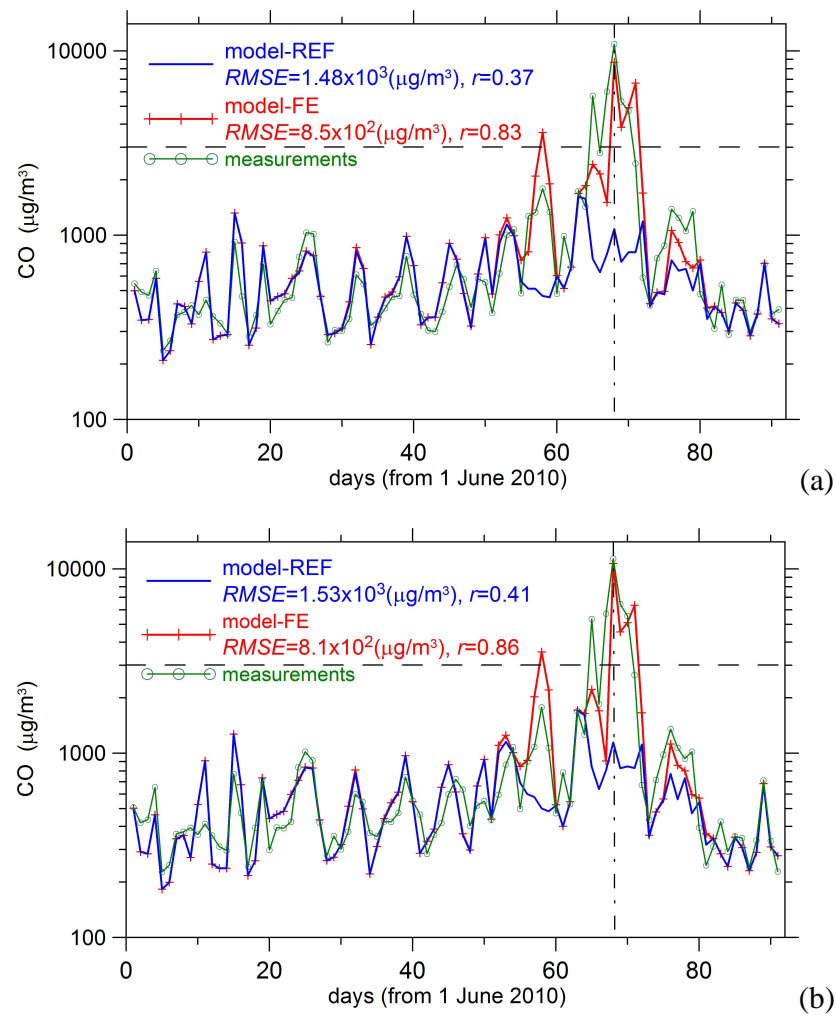

Fig. 6. Daily mean CO concentrations simulated by CHIMERE without (the REF run) and with (the FE run) wildfire emissions in comparison with corresponding measurements. Concentrations are averaged over monitoring sites (a) used in optimisation procedure and (b) employed only for validation of the modelling results. The dashed horizontal lines depict the threshold $\mathrm{CO}$ daily mean concentration defined by the Russian air quality standards, and the vertical dash-dot lines mark the 68th day (7 August). Note that concentrations are given on a logarithmic scale. Note also that although RMSE in the FE case is about as large as typical CO concentrations under normal conditions, it is a factor of ten less than the maximum $\mathrm{CO}$ concentration observed during the considered period. 

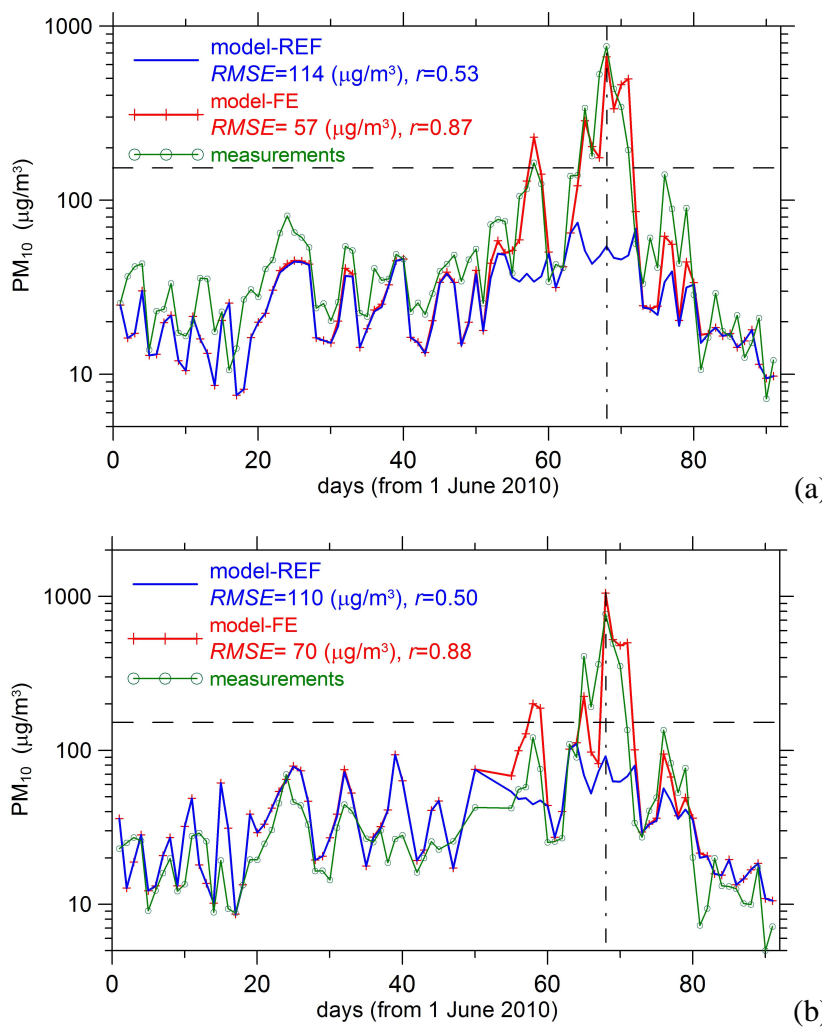

(b)

Fig. 7. The same as in Fig. 6 but for $\mathrm{PM}_{10}$ concentrations.

ern Russia from south. Maximum daily temperature mostly exceeded $30^{\circ} \mathrm{C}$ in July and August (see Fig. 9), surpassing record values registered in Moscow over a period of more than $100 \mathrm{yr}$. Note that the daily variations of observed temperature are closely reproduced by the model. A small underestimation (a few degrees) may be associated with unresolved local features of the meteorological station. Both the measured and modeled data show that there was almost no precipitation in July and in the beginning of August. The level of local precipitation is in general difficult to predict; differences between the measurements and calculations may reflect strong spatial variability of precipitation in the considered period.

Simulations taking into account wildfire emissions reproduce the $\mathrm{CO}$ and $\mathrm{PM}_{10}$ observations fairly well. Specifically, the correlation coefficient calculated for the daily time series exceeds 0.8 both for $\mathrm{CO}$ and $\mathrm{PM}_{10}$ and for all of the data subsets (sites used for the optimisation procedure and validation sites). Importantly, inclusion of fire emissions in the model leads to drastic improvements in agreement between the observed and simulated data. In particular, the root mean square error (RMSE) calculated for the validation subset of $\mathrm{CO}$ concentrations is reduced by more than $45 \%$ and the correlation coefficient increased from 0.41 to 0.86 . Although the reduction of RMSE is smaller for the validation subset of $\mathrm{PM}_{10}$ concentrations (about $36 \%$ ), the increase of the correlation

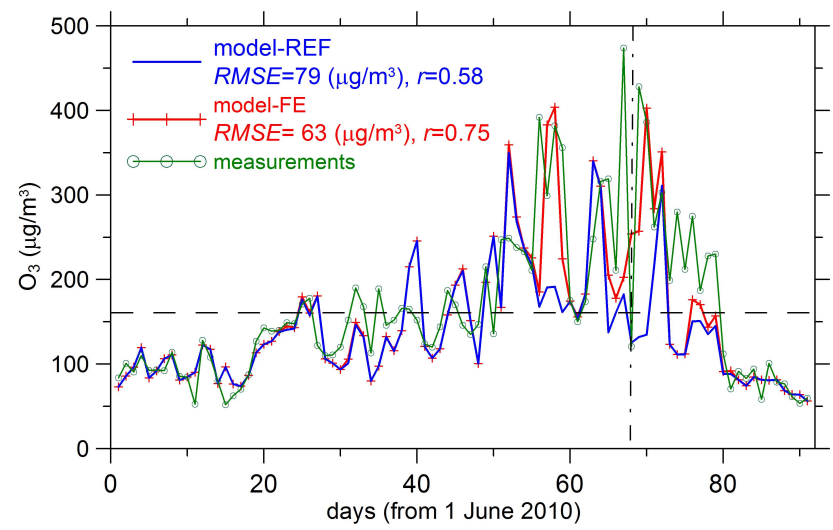

Fig. 8. Daily maximums of ozone concentrations simulated by CHIMERE without (the REF run) and with (the FE run) wildfire emissions in comparison with daily maximums of $1 \mathrm{~h}$ average ozone concentrations measured at the sites of Mosecomonitoring in the Moscow region. Each data point represents the largest value among daily maximum ozone concentrations at all of the ozone monitoring sites considered in this study. The dashed horizontal lines depict the threshold $\mathrm{O}_{3}$ concentration $\left(160 \mu \mathrm{g} \mathrm{m}^{-3}\right)$ defined by the Russian air quality standards, and the vertical dash-dot lines mark the 68th day (7 August).

coefficient is also quite impressive: from 0.5 to 0.88 . The reduction of RMSE for the optimisation subset of $\mathrm{PM}_{10}$ data is also large (about $50 \%$ ). The differences in results obtained with optimisation and validation subsets of $\mathrm{PM}_{10}$ data may be due to a considerable representativity error in our $\mathrm{PM}_{10}$ simulations which cannot be sufficiently reduced by averaging of $\mathrm{PM}_{10}$ concentrations over a few measurement sites.

The available measurement data did not allow us to validate the simulated chemical composition of aerosol particles. However, it is useful to note that according to our model results, a fraction of secondary aerosol in the atmosphere strongly perturbed by emissions from fires was typically rather small (less than 10 percent). Note also that an additional numerical experiment, in which the optimisation and validation procedures were repeated after "swapping" the optimisation and validation subsets of $\mathrm{CO}$ and $\mathrm{PM}_{10}$ monitors yielded very similar results; in this way, we checked that the model performance is not very sensitive to the choice of optimisation and validation sites.

In addition to the comparison of simulations and measurements of the daily mean $\mathrm{CO}$ and $\mathrm{PM}_{10}$ concentrations, we performed a similar comparison of the night time concentrations. Specifically, both the measured and simulated (with fire emissions) $\mathrm{CO}$ and $\mathrm{PM}_{10}$ concentrations were averaged over the period from 10:00 p.m. to 05:00 a.m. of the local time. Such processed simulations and measurements also demonstrated reasonable agreement (the correlation coefficients equals 0.59 and 0.61 in the $\mathrm{FE}$ case for validation subsets of the $\mathrm{CO}$ and $\mathrm{PM}_{10}$ data, respectively). In the period from 20 July to 20 August (when fires 


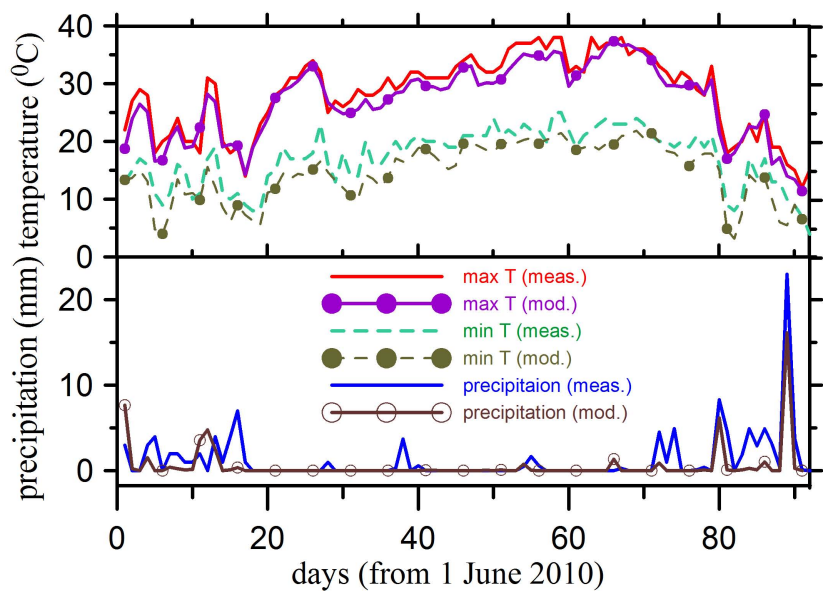

Fig. 9. Daily maximum and minimum of 2-m temperature and daily precipitation (lower panel) measured at the meteorological station situated in the Moscow State University and calculated with the MM5 model driven by the NCEP Reanalysis-2 data.

were most important) the measured night-time concentrations were slightly larger than the daily mean concentrations $\left(1.97 \times 10^{3}\right.$ vs. $1.88 \times 10^{3} \mu \mathrm{g} \mathrm{m}^{-3}$ for CO and $1.37 \times 10^{2}$ vs. $1.22 \times 10^{2} \mu \mathrm{g} \mathrm{m}^{-3}$ for $\mathrm{PM}_{10}$; the values are provided for the validation subset of the data). Similar differences are demonstrated by the model $\left(2.05 \times 10^{3}\right.$ vs. $1.81 \times 10^{3} \mu \mathrm{g} \mathrm{m}^{-3}$ for $\mathrm{CO}$ and $1.58 \times 10^{2}$ vs. $1.42 \times 10^{2} \mu \mathrm{g} \mathrm{m}^{-3}$ for $\mathrm{PM}_{10}$ ). These results indicate that mixing processes during night-time are well taken into account by the model.

Ozone simulations also improve after taking fire emissions into account, but to a smaller extent. Specifically, the correlation coefficient increases from 0.58 to 0.75 and RMSE decreases from 79 to $63 \mu \mathrm{g} \mathrm{m}^{-3}$. Smaller improvements of ozone simulations compared to the cases of $\mathrm{CO}$ and $\mathrm{PM}_{10}$ simulations may reflect strong temporal and spatial variability of ozone concentrations in the megacity region, especially in the presence of large perturbations of atmospheric composition due to fires. Some factors affecting the ozone behaviour are examined in Sect. 5.3.

Contribution of fires to air pollution in the Moscow region can be assessed as the difference between simulations performed with and without fire emissions. Evidently, the extreme air pollution episode in August was mainly caused by fires. Although stagnant meteorological conditions and high temperature which dominated in the Moscow region during July and August (see Fig. 9) favoured accumulation of primary pollutants and formation of secondary aerosols, our simulations in the REF case demonstrate that if wildfires would have been absent, the evolution of $\mathrm{CO}$ and $\mathrm{PM}_{10}$ concentrations would not have demonstrated any dramatic anomalies. On the other hand, the large impact of fires on air quality in Moscow was favoured by specific circulations patterns: additional analysis (not presented here) of the spatialtemporal evolution of the simulated concentration fields re-

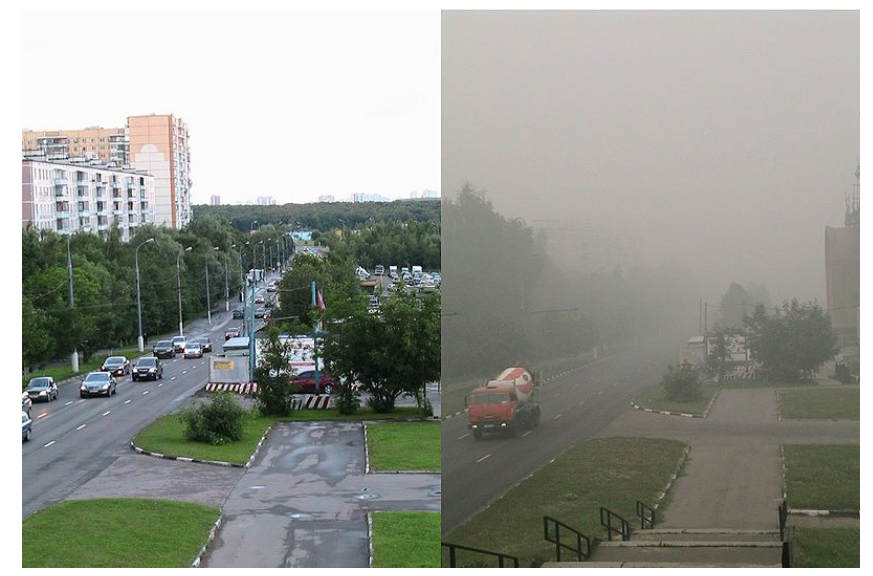

Fig. 10. Views of Moscow (Aivazovskogo str., Yasenevo) on 17 June 2010, 20:22 (left) and 7 August 2010, 17:05. Source: 2010 Russian Fires (2010). The picture is reproduced under the terms of the GNU Free Documentation License.

veals that the air pollution episode in Moscow in the period from 3 to 15 August was mainly caused by transport of smoke from intensive fires north to Ryazan (the city situated in $\sim 180 \mathrm{~km}$ south-east from Moscow). As an illustration, Fig. 11 presents the HYSPLIT (http://ready.arl.noaa. gov/hysplit-bin) backward trajectory analysis for 7 August, which confirms that the air transport to Moscow took place from south-east during the last day.

Ozone can be affected by wild fires at least in two different ways. First, wildfire emissions favor photochemical ozone formation by increasing ozone precursor levels $\left(\mathrm{NO}_{\mathrm{x}}\right.$, VOC, CO). Second, smoke aerosol absorbs solar radiations and thus inhibits ozone formation. The reference (REF) simulation presented in Fig. 8 was performed without fire emissions, but the impact of fires on photolytic reactions was still included (via the observational constraint as discussed above). In this case, unlike $\mathrm{CO}$ and $\mathrm{PM}_{10}$, ozone could still reach rather high values $\left(>300 \mu \mathrm{g} \mathrm{m}^{-3}\right)$. At the same time, the fire case (FE) run yields much higher (more than a factor of two) ozone concentrations than the REF run in two episodes (26-29 July and 4-11 August), clearly showing the impact of fire emissions. The impact of the shielding effect of aerosol on the ozone evolution is assessed in Sect. 5.3.

\subsection{Sensitivity tests}

In this section, we present results of several numerical experiments clarifying the role of different factors in the considered phenomena. First, we tried to better understand the origin of the extreme air pollution episodes in Moscow. For this purpose, we examined whether these episodes were caused by relatively local fires or were due to transport of air pollution from more distant regions. Specifically, we performed a test simulation (TEST_1) where wildfire emissions in a small region surrounding Moscow were put to zero. The region 


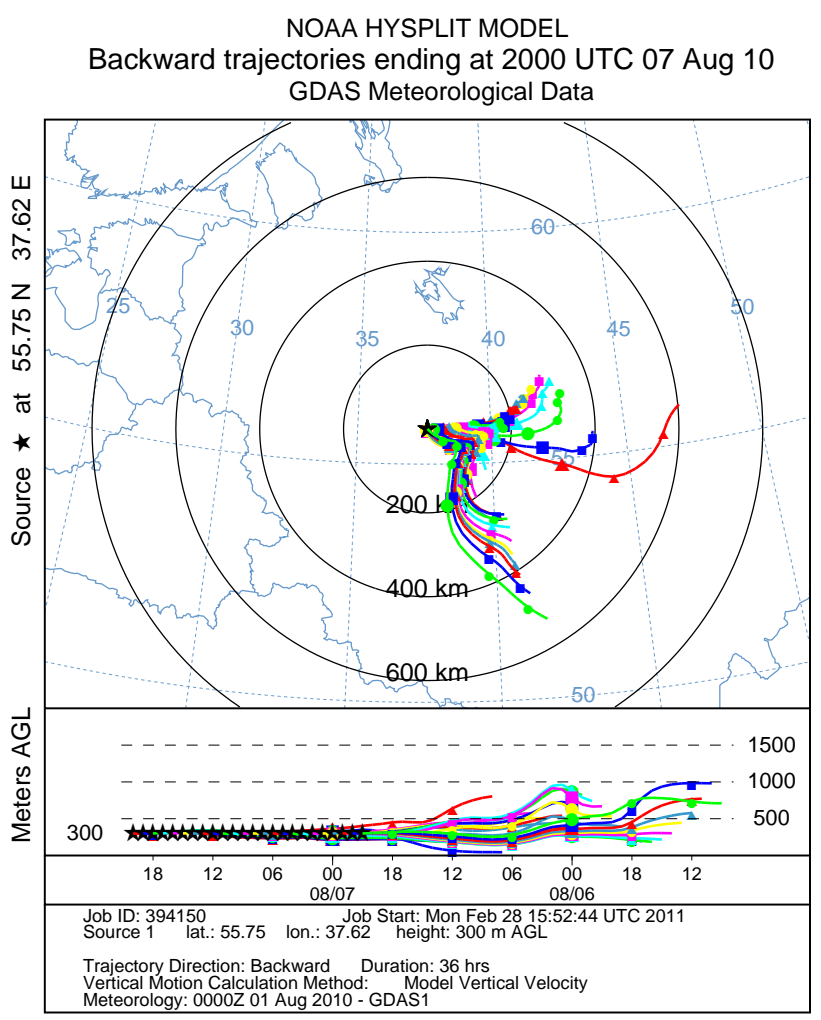

Fig. 11. HYSPLIT backward trajectories ending in Moscow at 7 August 2010. Different trajectories have different arrival time in the range from 6 August, 20:00 UTC to 7 August, 20:00 UTC. Note that 20:00 UTC corresponds to 24:00 LST (local summer time) in Moscow.

boundaries were defined as follows: $37^{\circ} \mathrm{E}, 41^{\circ} \mathrm{E}, 54.5^{\circ} \mathrm{N}$ and $56^{\circ} \mathrm{N}$, i.e. less than $200 \mathrm{~km}$ from Moscow. This region includes, in particular, locations of intensive fires near Ryazan (see Fig. 5f and h). Results presented in Fig. 12 unambiguously confirm that the extreme air pollution episodes in Moscow were caused by fires taking place at relatively short range from Moscow, although the impact of more distant fires is also not negligible, especially in the period from 7 to 11 August.

The goal of the next experiment is to justify the importance of the parameter $C(\tau)$, which is expected to compensate for a possible underestimation of FRP from fires obscured by smoke aerosols. In the case of $C(\tau)=1$, the optimization procedure described in Sect. 4.2 yielded the following values of the correction factors for $\mathrm{CO}$ fire emissions: $F_{1}=0.93$ and $F_{2}=-1.3$. Negative values of emissions from peat fires are physically unacceptable, and this result is evidence that if the impact of smoke aerosols on the FRP measurements is disregarded, the emission model defined by Eq. (5) becomes inadequate. With $C(\tau)=1$ and $F_{2}$ fixed at zero, we found that the optimal value of $F_{1}$ is 0.88 . The corresponding CO concentrations are presented in Fig. 13. Evidently, the per-

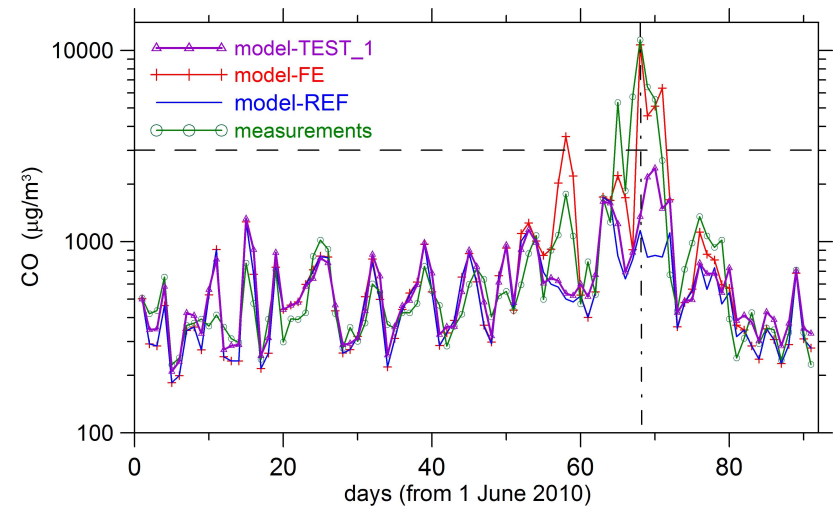

Fig. 12. Daily mean CO concentrations obtained as a result of the TEST_1 simulation where wildfire emissions in a region surrounding Moscow were put to zero (see the text for the region definition) in comparison with concentrations simulated in the FE and REF runs of the model and observed in the validation monitoring sites. Concentrations are averaged over validation subset of monitoring sites. The dashed horizontal line depicts the threshold $\mathrm{CO}$ daily mean concentration defined by the Russian air quality standards, and the vertical dash-dot line marks the 68th day (7 August).

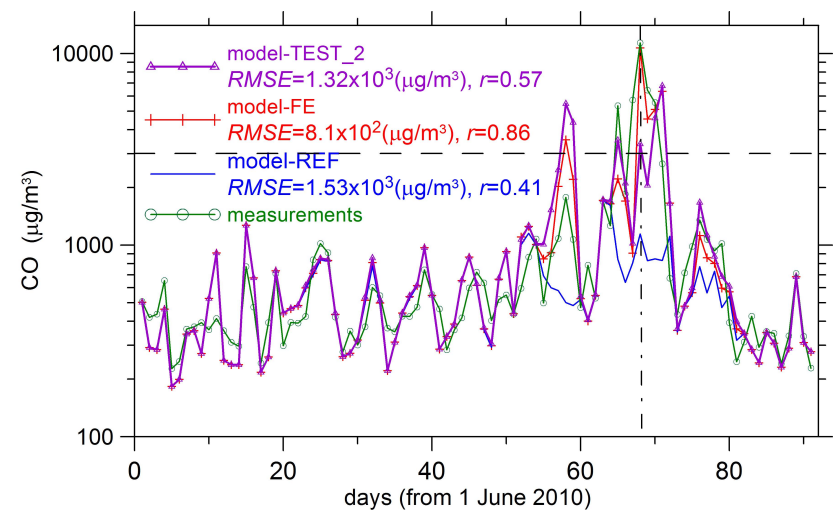

Fig. 13. The same as in Fig. 12 except that the test simulations (the TEST_2 run) were performed with $C(\tau)=1$ (see Eq. 5).

formance of the simulations is much worse in the test case than in the base (FE) case. Therefore, this test justifies the proposed parameterization of $C(\tau)$, even though we cannot claim that it is the best possible.

The next experiments examine the impact of the shielding effect of smoke aerosols on the evolution of surface ozone in the Moscow region. Simulations were performed for the TEST_3 and TEST_4 cases which were the same as the reference (REF) and base (FE) cases discussed above (that is, without and with fire emissions), respectively, except that the effect of aerosol on photolysis rates was disregarded. The results presented in Fig. 14 indicate that even if fires were absent, ozone concentration in the Moscow region under very hot, stagnant and cloudless conditions of August 2010 could reach very high values. Comparison of the TEST_3 and 


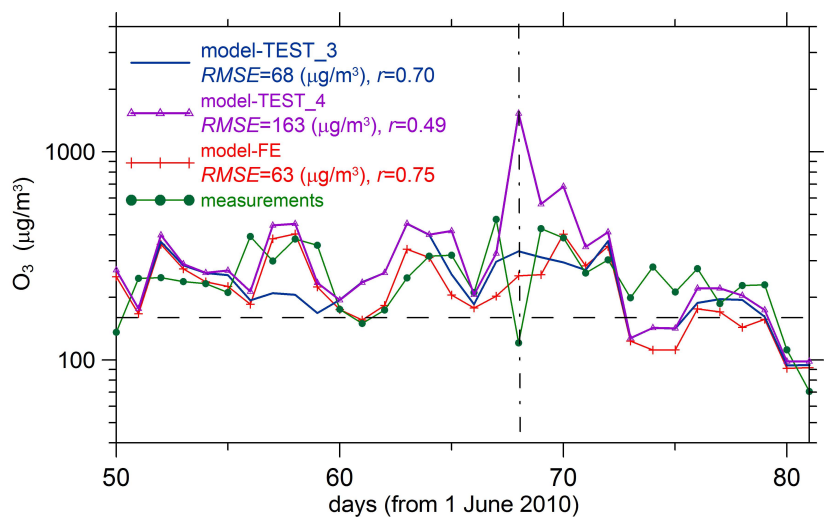

Fig. 14. The same as in Fig. 8, except that instead of results for the REF run, the simulated data are presented for the two test cases (see Table 1 and Sect. 5.3 for definitions). For better readability, only the period most affected by fires is shown (from 20 July to 20 August 2010), although the statistics are evaluated for the whole period considered in this study.

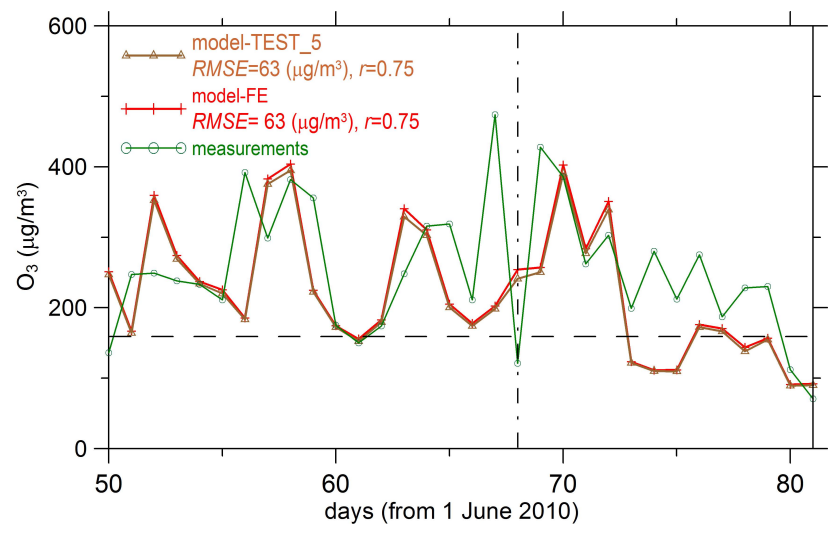

Fig. 15. The same as in Fig. 14, but instead of results for the test cases 3 and 4, the simulated data are presented for the TEST_5 case where an SSA value of 0.8 is used instead of 0.95 in the FE case.

TEST_4 results with the base case (FE) simulations confirms that wildfires strongly affected ozone formation in the two ways, namely by providing a powerful source of ozone precursors and, at the same time, inhibiting its formations as a result of absorption of solar radiation by smoke aerosols. The net result of these two effects was different in different conditions. Note that the extremely high and unrealistic level of ozone concentration reached in the TEST_4 case may reflect a nonlinear interaction of ozone with its precursors. Namely, large fire emissions of VOC may counterbalance large anthropogenic $\mathrm{NO}_{\mathrm{x}}$ emissions inhibiting ozone formation and contribute to even larger production of ozone. This makes again evident the importance of the shielding effect.

The purpose of a final test (the TEST_5 case) is to assess ozone sensitivity to the single scattering albedo (SSA) value specified in our model. Figure 15 presents the ozone evolution simulated as in the FE case but with a considerably
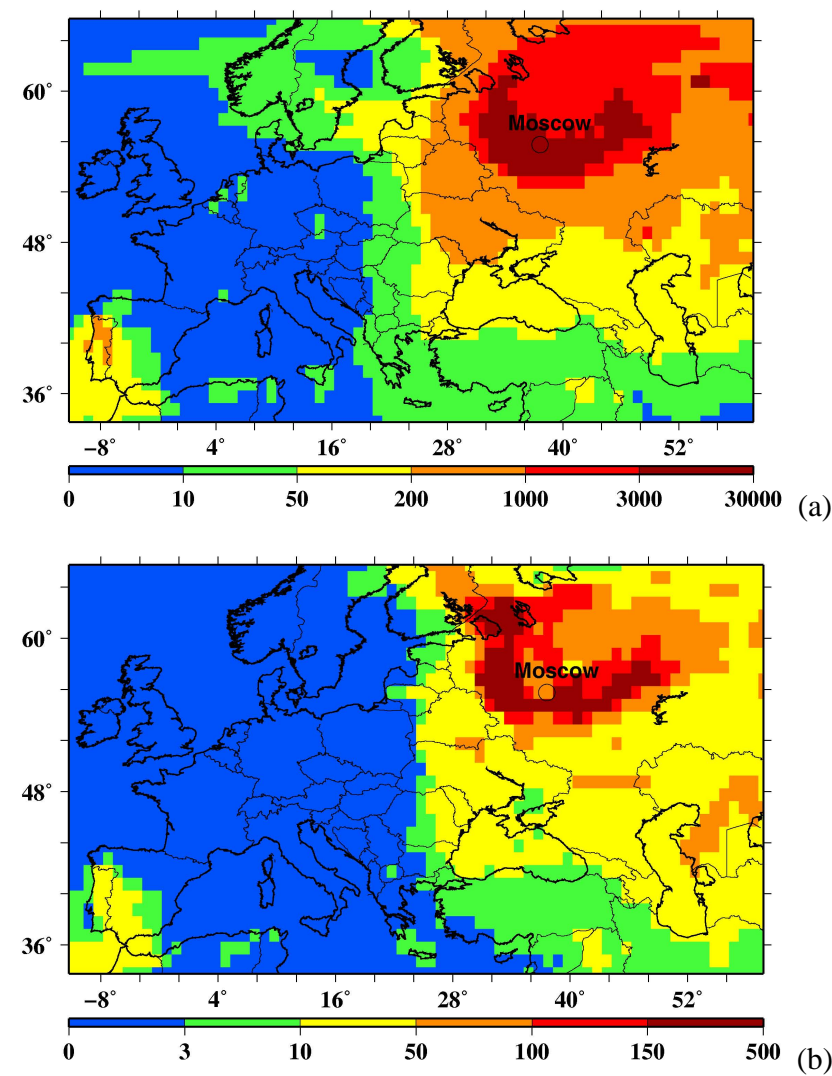

(b)

Fig. 16. Maximum perturbations in (a) daily mean $\mathrm{CO}$ and (b) daily maximum $\mathrm{O}_{3}$ concentrations due to wildfires in summer 2010. The perturbations (in $\mu \mathrm{g} \mathrm{m}^{-3}$ ) are estimated as differences of the respective concentrations simulated in the FE and TEST_3 cases; the latter is used to represent the atmosphere unperturbed by fires.

smaller SSA value of 0.8 representing the case of strongly absorbing smoke aerosol which was observed by Meloni et al. (2006) in comparison with the ozone time series obtained in the FE case (with SSA=0.95). Note that the AOD values specified for our photolysis rate calculations from the MODIS measurements were the same in the both simulations. Evidently, ozone concentrations calculated with the smaller SSA value are only very insignificantly lower than in the base case (the differences in ozone concentrations do not exceed 7 percent). Even much smaller differences were found in concentrations of $\mathrm{CO}$ and $\mathrm{PM}_{10}$. Therefore, we can conclude that results of our simulations would not be significantly affected by possible variations of SSA of smoke aerosol in the real atmosphere.

\subsection{Air pollution episodes in the Moscow region from a continental scale perspective}

The severe air pollution episodes observed in the Moscow region were only a part of a strong perturbation in the atmospheric composition caused by wildfires in Russia. To get an idea about the spatial extent of these perturbations and 

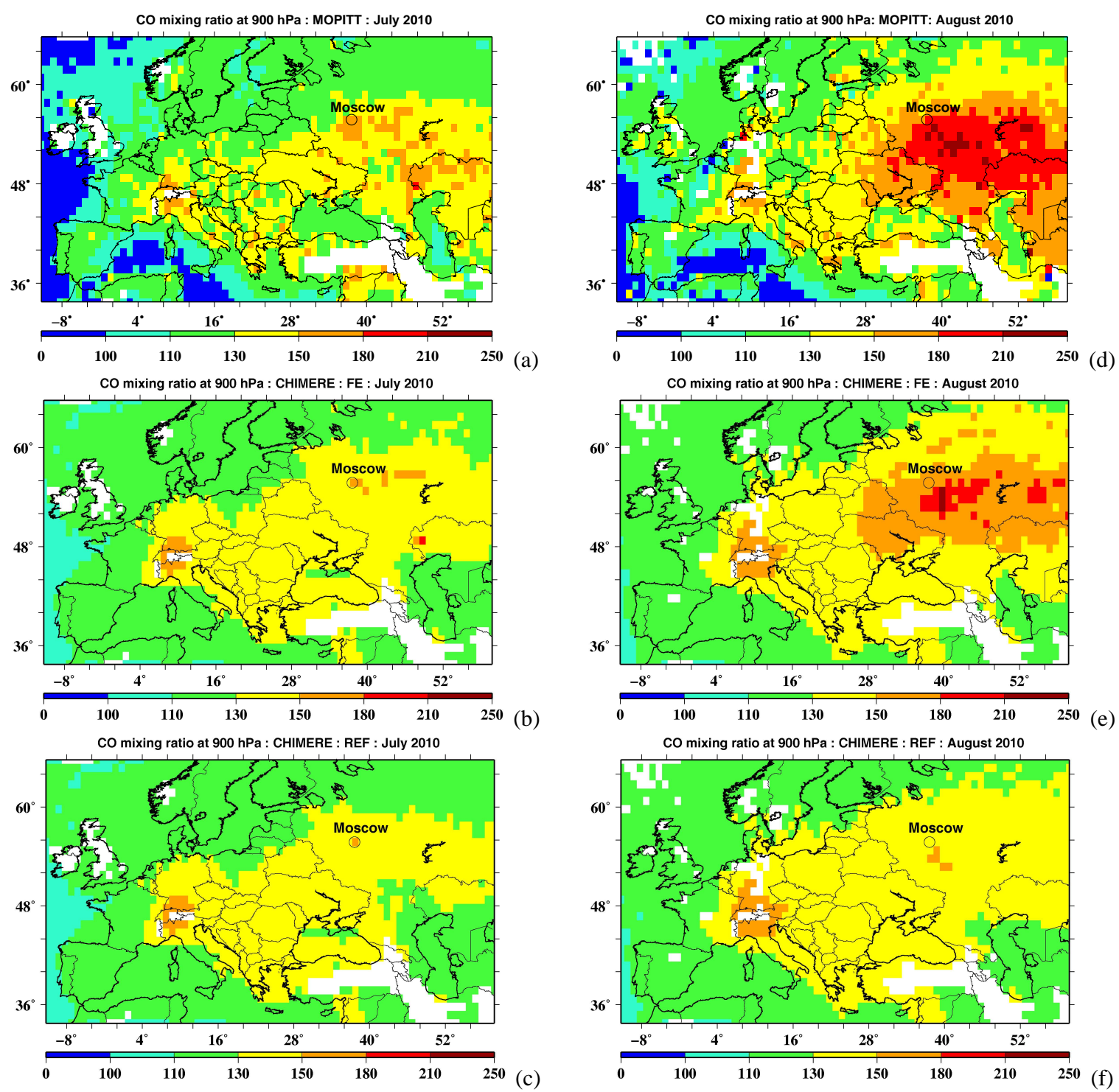

Fig. 17. Spatial distributions of monthly mean CO mixing ratio at the nominal $900 \mathrm{hPa}$ MOPITT pressure level in July (a-c) and August (d-f) 2010. The MOPITT data (a,d) are shown in comparison with simulated CO mixing ratios (corrected for a systematic bias) with (b, e) and without (c, f) fire emissions.

to evaluate representativity of the phenomena observed in Moscow within a more general picture, we estimated maximum perturbations in daily mean $\mathrm{CO}$ and daily maximum $\mathrm{O}_{3}$ concentrations due to wildfires in summer 2010 by using simulations performed with the large (continental) domain of our model. Specifically, we calculated the maximum differences between the FE and TEST_3 cases; the latter is used to represent the atmosphere unperturbed by fires. The results are presented in Fig. 16. According to these results, the level of the considered pollutants was considerably enhanced (at least episodically) over the most of European Russia, but also over parts of Ukraine, Belorussia, Baltic states and Finland. The transport of air pollution from Russia further to Western Europe was small.
The direct validation of these modeling results is difficult due to the lack of available air quality monitoring data. However, the fact that the composition of the lower atmosphere during the considered period was indeed very strongly perturbed over a large region can be confirmed by satellite measurements. Figure 17 presents the spatial distributions of the CO mixing ratio at $900 \mathrm{hPa}$, derived from MOPITT measurements in comparison with the corresponding distributions of the simulated data. The modeled data were preliminary processed with MOPITT averaging kernels as explained in Sect. 3.2. The MOPITT measurements show that the CO level was strongly enhanced over most of the European part of Russia in August. The huge CO "cloud" also covered parts of Belarus and Ukraine. The model reproduces the location 
of the maximum $\mathrm{CO}$ mixing ratio perturbation in the southeast of Moscow reasonably well, but underestimates its magnitude even after correction of the systematic bias over the whole domain (which is about $16 \mathrm{ppb}$ ). It appears that the $\mathrm{CO}$ distribution from the model is much smoother than that from MOPITT. The model also underestimates the $\mathrm{CO}$ mixing ratios in the southern part of the domain. Nonetheless, it is important that inclusion of fire emissions into our model improves the agreement between the simulated and measured variation of $\mathrm{CO}$ mixing ratios at the continental scale.

When discussing systematic differences between the measured and modeled CO mixing ratio, it should be considered that $900 \mathrm{hPa}$ MOPITT measurements are actually sensitive to $\mathrm{CO}$ over the whole troposphere, as explained in Sect. 3.2. For instance, the mean (over the whole model domain and the summer 2010 season) sensitivity to $\mathrm{CO}$ at $500 \mathrm{hPa}$ is still as large as that at $900 \mathrm{hPa}$. Pfister et al. (2004) detected an even larger positive systematic difference than in our study (up to $30 \mathrm{ppb}$ in summer) between $\mathrm{CO}$ mixing ratios from $\mathrm{MO}$ PITT and the MOZART global CTM and found that only $8 \%$ of $\mathrm{CO}$ at $500 \mathrm{hPa}$ over Europe originated from European emissions. Accordingly, one probable reason for the bias detected in this study is a systematic underestimation of monthly average climatological CO lateral and top boundary conditions that are indeed taken from MOZART. To examine the role of boundary conditions in our simulations, we have performed a model run with zero $\mathrm{CO}$ at the top and lateral boundaries. In this simulation, and under unperturbed conditions (without fires) the average $\mathrm{CO}$ mixing ratios at $900 \mathrm{hPa}$ (processed with the MOPITT averaging kernels) are then decreased by more than a factor of three over the CER region in July and August. This test confirms a strong impact of the boundary conditions on the model results which potentially could explain the differences with MOPITT measurements. Pfister et al. (2004) also argue that a significant part of the mentioned difference is due to an underestimation of anthropogenic $\mathrm{CO}$ emissions in their model. Thus, both anthropogenic $\mathrm{CO}$ emissions, but also advection through model boundaries, are potential error sources, in addition to uncertainties in the fire emissions and their vertical distribution in the troposphere. In spite of certain differences with the satellite measurements, the simulations confirm the role of fires as the principal reason for the extreme air pollution observed over Russia in August 2010.

\section{Conclusions}

The CHIMERE chemistry transport model in combination with satellite data and ground based measurements was used in order to analyze episodes of extreme air pollution in the Moscow megacity region in summer 2010, when maximum measured daily average $\mathrm{CO}$ and $\mathrm{PM}_{10}$ concentrations reached $20 \mathrm{mg} \mathrm{m}^{-3}$ and $0.9 \mathrm{mg} \mathrm{m}^{-3}$, respectively. The model was modified to take into account wildfire emissions and reduction of photolysis rates due to the assumed shielding effect of aerosols. The wildfire emission estimates derived from the MODIS FRP measurements were optimized by assimilating data of air pollution monitoring in Moscow into the model. Specifically, we optimized two factors relating FRP data to rates of wildfire emissions separately from peat land and other types of vegetative land cover. In this way, we managed to estimate both total wildfire emissions and emissions from peat fires. The impact of smoke aerosols on photolysis rates was taken into account using the TUV model with the aerosol optical depth (AOD) measured by MODIS at $550 \mathrm{~nm}$ and assuming an aerosol single scattering albedo of 0.95 . The MODIS AOD measurements were used also to correct a possible negative bias in FRP measurements in case of fires obscured by heavy smoke.

Validation of the model results was performed by comparing them with independent monitoring data which were withheld during the optimisation procedure. It is demonstrated that the optimized simulations reproduce $\mathrm{PM}_{10}$ and $\mathrm{CO}$ monitoring data rather adequately. Specifically, the correlation coefficient $(r)$ of daily time series of $\mathrm{CO}$ and $\mathrm{PM}_{10}$ exceeds 0.85 . Strong temporal variability of the measured ozone daily maxima is not always closely reproduced by the model, but in general the agreement between time series of the simulated and measured ozone concentrations is also rather satisfactory $(r=0.75)$.

It is also found that inclusion of fire emissions into the model considerably improves its performance at the surface. In particular, the correlation coefficient calculated for daily $\mathrm{CO}$ concentrations in the validation data subset has increased from 0.41 up to 0.86 , and RMSE has been reduced from 1.53 to $0.81 \mathrm{mg} \mathrm{m}^{-3}$. Similar large improvements are found for daily $\mathrm{PM}_{10}$ concentrations. Smaller but also considerable improvements are achieved in ozone simulations (specifically, the correlation coefficient calculated for ozone daily maximums has increased from 0.58 up to 0.75 , and RMSE has been reduced from 79 to $63 \mu \mathrm{g} \mathrm{m}^{-3}$. Therefore, this study demonstrated the feasibility of using fire emission estimates derived from satellite FRP measurements to simulate the daily variability of air pollution in a megacity region.

The comparison of model results obtained without and with fire emissions showed that stagnant and dry meteorological conditions favoured accumulation of anthropogenic pollution during the observed episodes of extremely high concentrations of $\mathrm{CO}$ and $\mathrm{PM}_{10}$ in the Moscow region, but anthropogenic sources could not compete with the huge wildfire emissions of these pollutants. On the contrary, our diagnostic simulations revealed that ozone concentrations could reach large values $\left(>400 \mu \mathrm{g} \mathrm{m}^{-3}\right)$ even without fire emissions. Fires provided a powerful source of ozone precursors but, at the same time, inhibited ozone formation as a result of absorption and scattering of solar radiation by smoke aerosol.

Additional numerical experiments aimed at clarifying the role of different factors in the considered phenomena. In particular, it was found that the extreme air pollution episodes 
in Moscow were mainly caused by fires taking place at relatively short range (less than $200 \mathrm{~km}$ ) from Moscow; the transport of air pollution to Moscow from more distant (although also intensive) fires was less significant. It was also found that a compensation of a possible negative bias in the measured radiative power from fires obscured by heavy smoke is a crucial condition for a good performance of the model.

The MOPITT CO measurements and corresponding simulations indicate that the observed episodes of extreme air pollution in Moscow were only a part of a very strong perturbation of the atmospheric composition, caused by wildfires, over the largest part of European Russia. Wildfire emission estimates consistent with the measurements in the Moscow region suggest that fires in Western Russia emitted more than $85 \%(\sim 10 \mathrm{Tg})$ of the total annual anthropogenic CO emissions in the same region. On the whole, this study demonstrated that wildfires can play a crucial role for air pollution even in large megacity regions otherwise strongly affected by anthropogenic air pollution. Efforts to properly address atmospheric effects associated with wildfires in chemistry transport models should be continued in future studies. In particular, heterogeneous reactions occurring on fire emitted aerosols should be included into the model.

Acknowledgements. The authors are grateful to SEI Mosecomonitoring and, in particular, to E. G. Semutnikova for providing air pollution monitoring data. The support for this study was provided by the Russian Foundation for Basic Research (grants No. 1105-91061-CNRS, 11-05-97003-r), Russian Academy of Sciences in the framework of the Programme for Basic Research "Electrodynamics of atmosphere; Electrical Processes, Radiophysical Methods of Research", Russian Federal Special Program "Scientific and scientifically-pedagogical staff of innovative Russia" in 2009-2013 (contracts 02.740.11.0732, P2318), the Government of the Russian Federation under the agreement No. 11.G34.31.0014, and European Union's Seventh Framework Programme within the MEGAPOLI project (grant agreement No. 212520).

Edited by: M. Gauss

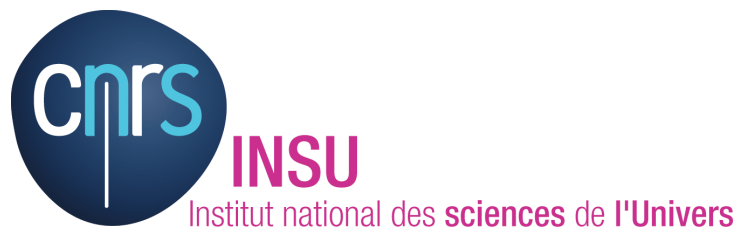

The publication of this article is financed by CNRS-INSU.

\section{References}

2010 Russian wildfires: Wikipedia, The Free Encyclopedia, http: //en.wikipedia.org (last access: February 2011), 2011.

Akagi, S. K., Yokelson, R. J., Wiedinmyer, C., Alvarado, M. J., Reid, J. S., Karl, T., Crounse, J. D., and Wennberg, P. O.: Emission factors for open and domestic biomass burning for use in atmospheric models, Atmos. Chem. Phys., 11, 4039-4072, doi:10.5194/acp-11-4039-2011, 2011.

Andreae, M. O. and Merlet, P.: Emission of trace gases and aerosols from biomass burning, Global Biogeochem. Cy., 15, 955-966, 2001.

Aumont, B., Chervier, F., and Laval, S.: Contribution of HONO to the $\mathrm{NO}_{\mathrm{x}} / \mathrm{HO}_{\mathrm{x}} / \mathrm{O}_{3}$ chemistry in the polluted boundary layer, Atmos. Environ., 37, 487-498, 2003.

Baklanov, A., Grimmond, S., Mahura, A., and Athanassiadou, M. (Eds.): Meteorological and air quality models for urban areas, Springer, Berlin, 2009.

Barbu, A. L., Segers, A. J., Schaap, M., Heemink, A. W., and Builtjes, P. J. H.: A multi-component data assimilation experiment directed to sulphur dioxide and sulphate over Europe, Atmos. Environ., 43, 1622-1631, doi:10.1016/j.atmosenv.2008.12.005, 2009.

Beekmann, M. and Vautard, R.: A modelling study of photochemical regimes over Europe: robustness and variability, Atmos. Chem. Phys., 10, 10067-10084, doi:10.5194/acp-1010067-2010, 2010.

Bessagnet, B., Menut, L., Aymoz, G., Chepfer, H., and Vautard, R.: Modelling dust emissions and transport within Europe: the Ukraine March 2007 event, J. Geophys. Res.-Atmos., 113, D15202, doi:10.1029/2007JD009541, 2008.

Christian, T. J., Kleiss, B., Yokelson, R. J., Holzinger, R., Crutzen, P. J., Hao, W. M., Saharjo, B. H., and Ward, D. E.: Comprehensive laboratory measurements of biomass-burning emissions: 1. Emissions from Indonesian, African, and other fuels, J. Geophys. Res., 108, 4719, doi:10.1029/2003JD003704, 2003.

Chubarova, N. Y., Prilepsky, N. G., Rublev, A. N., and Riebau, A. R.: A mega-fire event in central Russia: fire weather, radiative, and optical properties of the atmosphere, and consequences for subboreal forest plants, in: Developments in Environmental Science. V. 8, edited by: Bytnerowicz, A., Arbaugh, M., Riebau, A., and Andersen, C., 247-264, 2009.

Chubarova, N., Smirnov, D. R., and Holben, B. N.: Aerosol properties in Moscow according to 10 years of AERONET measurements at the Meteorological Observatory of Moscow State University, Geography, Environment, Sustainability, in press, 2011.

Crutzen, P. J. and Andreae, M. O.: Biomass burning in the tropics: Impact on atmospheric chemistry and biogeochemical cycles, Science, 250, 1669-1678, 1990.

Deeter, M. N. and MOPITT algorithm development team: MOPITT (Measurements of Pollution in the Troposphere) validated version 4 product user's guide, NCAR, Boulder, 2009.

Dickerson, R. R., Kondragunta, S., Stenchikov, G., Civerolo, K. L., Doddridge, B. G., and Holben, B. N.: The impact of aerosols on solar ultraviolet radiation and photochemical smog, Science, 278, 827-830, 1997.

Elbern, H., Strunk, A., Schmidt, H., and Talagrand, O.: Emission rate and chemical state estimation by 4-dimensional variational inversion, Atmos. Chem. Phys., 7, 3749-3769, doi:10.5194/acp7-3749-2007, 2007. 
EMEP: Transboundary acidification, eutrophication and ground level ozone in Europe in 2008, Joint MSC-W \& CCC \& CEIP Report, EMEP Status Report 1/10, 2010.

Enting, I. G.: Inverse problems in atmospheric constituents transport, Cambridge University Press, 2002.

Eskes, H. J., Piters, A. J. M., Levelt, P. F., Allart, M. A. F., and Kelder, H. M.: Variational assimilation of total-column ozone satellite data in a 2D lat-lon tracer-transport model, J. Atmos. Sci., 56, 3560-3572, 1999.

Giglio, L.: MODIS Collection 5 Active Fire Product User's Guide, Science Systems and Applications, Inc., University of Maryland, 2010.

Giglio, L., van der Werf, G. R., Randerson, J. T., Collatz, G. J., and Kasibhatla, P.: Global estimation of burned area using MODIS active fire observations, Atmos. Chem. Phys., 6, 957974, doi:10.5194/acp-6-957-2006, 2006.

Ginoux, P., Chin, M., Tegen, I., Prospero, J. M., Holben, B., Dubovik, O., and Lin, S.-J.: Sources and distributions of dust aerosols simulated with the GOCART model, J. Geophys. Res., 106, 20255-20273, 2001.

Gorchakov, G. I., Semutnikova, E. G., Zotkin, E. V., Karpov, A. V., Lezina, E. A., and Ul'yanenko, A. V.: Variations in Gaseous Pollutants in the Air Basin of Moscow, Izvestiya, Atmos. Ocean. Phys., 42, 156-170, 2006.

GPW: Global Population of the World, version 3, SEDAC, http: //sedac.ciesin.columbia.edu/gpw (last access: February 2011), 2010.

Grégoire, J. M., Tansey, K., and Silva, J. M. N.: The GBA2000 initiative: developing a global burnt area database from SPOTVEGETATION imagery, Int. J. Remote. Sens., 24, 1369-1376, doi:10.1080/0143116021000044850, 2003.

Hao, W. M., Ward, D. E., Olbu, G., and Baker, S. P.: Emissions of $\mathrm{CO}_{2}, \mathrm{CO}$, and hydrocarbons from fires in diverse African savanna ecosystems, J. Geophys. Res.-Atmos., 101, 23577-23584, 1996.

Hodzic, A., Vautard, R., Bessagnet, B., Lattuati, M., and Moreto, F.: Long-term urban aerosol simulation versus routine particulate matter observations, Atmos. Environ., 39, 5851-5864, 2005.

Hodzic, A., Madronich, S., Bohn, B., Massie, S., Menut, L., and Wiedinmyer, C.: Wildfire particulate matter in Europe during summer 2003: meso-scale modeling of smoke emissions, transport and radiative effects, Atmos. Chem. Phys., 7, 4043-4064, doi:10.5194/acp-7-4043-2007, 2007.

Horowitz, L. W., Walters, S., Mauzerall, D. L., Emmons, L. K., Rasch, P. J., Granier, C., Tie, X., Lamarque, J.-F., Schultz, M. G., Tyndall, G. S., Orlando, J. J., and Brasseur, G. P.: A global simulation of ozone and related tracers: description and evaluation of MOZART, Version 2, J. Geophys. Res., 108, 4784, doi:10.1029/2002JD002853, 2003.

Ichoku, C. and Kaufman, J. Y.: A method to derive smoke emission rates from MODIS fire radiative energy measurements, IEEE T. Geosci. Remote, 43, 2636-2649, 2005.

Ichoku, C., Remer, L. A., and Eck, T. F.: Quantitative evaluation and intercomparison of morning and afternoon Moderate Resolution Imaging Spectroradiometer (MODIS) aerosol measurements from Terra and Aqua, J. Geophys. Res., 110, D10S03, doi:10.1029/2004JD004987, 2005.

Iinuma, Y., Brüggemann, E., Gnauk, T., Müller, K., Andreae, M. O., Helas, G., Parmar, R., and Herrmann, H.: Source charac- terization of biomass burning particles: The combustion of selected European conifers, African hardwood, savanna grass, and German and Indonesian peat, J. Geophys. Res., 112, D08209, doi:10.1029/2006JD007120, 2007.

Jacob, D. J.: Heterogeneous chemistry and tropospheric ozone,Atmos. Environ., 34, 2131-2159, 2000.

Jain, A. K., Tao, Z. N., Yang, X. J., and Gillespie, C.: Estimates of global biomass burning emissions for reactive greenhouse gases (CO, NMHCs, and $\mathrm{NO}_{\mathrm{x}}$ ) and $\mathrm{CO}_{2}$, J. Geophys. Res.-Atmos., 111, D06304, doi:10.1029/2005JD006237, 2006.

Jeong, J. I., Park, R. J., and Youn, D.: Effects of Siberian forest fires on air quality in East Asia during May 2003 and its climate implication, Atmos. Environ., 42, 8910-8922, doi:10.1016/j.atmosenv.2008.08.037, 2008.

Kadygrov, E. N., Kuznetsova, I. N., and Golitsyn, G. S.: Heat Island in the Boundary Atmospheric Layer over a Large City: New Results Based on Remote Sensing Data, Doklady Earth Sciences 385A, 688-694, 2002.

Kaiser, J. W., Suttie, M., Flemming, J., Morcrette, J.-J., Boucher, O., and Schultz, M. G.: Global Real-time Fire Emission Estimates Based on Space-borne Fire Radiative Power Observations, CP1100, in: Current Problems in Atmospheric Radiation (IRS 2008) edited by: Nakajima, T. and Yamasoe, M. A., American Institute of Physics, NY, 645-648, 2009.

Kaufmann, Y. J., Tanre, D., Remer, L. A., Vermote, E. F., Chu, A., and Holben, B. N.: Operational remote sensing of tropospheric aerosol over land from EOS moderate resolution imaging spectroradiometer, J. Geophys. Res., 102, 17051-17067, 1997.

Kaufman, Y. J., Justice, C. O., Flynn, L. P., Kendall, J. D., Prins, E. M., Giglio, L., Ward, D. E., Menzel, W. P., and Setzer, A. W.: Potential global fire monitoring from EOS-MODIS, J. Geophys. Res., 103, 32215-32238, 1998.

Key, J.: Streamer User's Guide, Cooperative Institute for Meteorological Satellite Studies, University of Wisconsin, 96 pp., 2001.

Khaikine, M. N., Kuznetsova, I. N., Kadygrov, E. N., and Miller, E. A.: Investigation of temporal-spatial parameters of an urban heat island on the basis of passive microwave remote sensing, Theor. Appl. Climatol., 84, 161-169, 2006.

Konovalov, I. B., Beekmann, M., Vautard, R., Burrows, J. P., Richter, A., Nüß, H., and Elansky, N.: Comparison and evaluation of modelled and GOME measurement derived tropospheric $\mathrm{NO}_{2}$ columns over Western and Eastern Europe, Atmos. Chem. Phys., 5, 169-190, doi:10.5194/acp-5-169-2005, 2005.

Konovalov, I. B., Beekmann, M., Richter, A., and Burrows, J. P.: Inverse modelling of the spatial distribution of $\mathrm{NO}_{\mathrm{x}}$ emissions on a continental scale using satellite data, Atmos. Chem. Phys., 6, 1747-1770, doi:10.5194/acp-6-1747-2006, 2006a.

Konovalov, I. B., Beekmann, M., Richter, A., and Burrows, J. P.: The use of satellite and ground based measurements for estimating and reducing uncertainties in the spatial distribution of emissions of nitrogen oxides, arXiv: physics/0612144, available at: www.arxiv.org, 2006b.

Konovalov, I. B., Beekmann, M., Burrows, J. P., and Richter, A.: Satellite measurement based estimates of decadal changes in European nitrogen oxides emissions, Atmos. Chem. Phys., 8, $2623-$ 2641, doi:10.5194/acp-8-2623-2008, 2008.

Konovalov, I. B., Elanskii, N. F., Zvyagintsev, A. M., Belikov, I. B., and Beekmann, M.: Validation of chemistry transport model of the lower atmosphere in the Central European region of Russia 
using ground-based and satellite measurement data, Russ. Meteorol. Hydrol., 34, 236-242, 2009.

Konovalov, I. B., Beekmann, M., Richter, A., Burrows, J. P., and Hilboll, A.: Multi-annual changes of $\mathrm{NO}_{\mathrm{x}}$ emissions in megacity regions: nonlinear trend analysis of satellite measurement based estimates, Atmos. Chem. Phys., 10, 8481-8498, doi:10.5194/acp-10-8481-2010, 2010.

Kuznetsova, I. N., Zaripov, R. B., Konovalov, I. B., Zvyagintsev, A. M., Semutnikova, E. G., and Artamonova, A. A.: The computational complex including a mesoscale atmospheric model and a chemistry transport model as a module of the air quality assessment system, Atmos. Ocean. Opt., 23, 485-492, 2010.

Kuznetsova, I. N., Konovalov, I. B., Artamonova, A. A., Nakhaev, M. I., Lezina, E. A., Zvyagintsev, A. M., and Beekmann, M.: The observed and simulated variability of $\mathrm{PM}_{10}$ concentration in Moscow and Zelenograd, Russ. Meteorol. Hydrol., 36, 175-184, doi:10.3103/S1068373911030046, 2011.

Langmann, B., Duncan, B., Textor, C., Trentmann, J., and van der Werf, G. R.: Vegetation fire emissions and their impact on air pollution and climate, Atmos. Environ., 43 107-116, doi:10.1016/j.atmosenv.2008.09.047, 2009.

Larkin, N. K., O’Neill, S. M., Solomon, R., Raffuse, S., Strand, T., Sullivan, D. C., Krull, C., Rorig, M., Peterson, J. L., and Ferguson, S. A.: The BlueSky smoke modeling framework, Int. J. Wildland Fire, 18, 906-920, 2009.

Lattuati, M.: Contribution à l'étude du bilan de l'ozone troposphérique à l'interface de l'Europe et de l'Atlantique Nord: Modélisation lagrangienne et mesures en altitude, Ph.D. Thesis, Université Paris 6, Paris, 1997.

Madronich, S., McKenzie, R. E., Bjorn, L. O., and Caldwell, M. M.: Changes in biologically active ultraviolet radiation reaching the earth's surface, J. Photochem. Photobiol. B, 46, 5-19, 1998.

Martin, R. V., Jacob, D. J., Yantosca, R. M., Chin, M., and Ginoux, P.: Global and regional decreases in tropospheric oxidants from photochemical effects of aerosols, J. Geophys. Res., 108, 4097, doi:10.1029/2002JD002622, 2003.

Meloni, D., di Sarra, A., Pace, G., and Monteleone, F.: Aerosol optical properties at Lampedusa (Central Mediterranean), 2. Determination of single scattering albedo at two wavelengths for different aerosol types, Atmos. Chem. Phys., 6, 715-727, doi:10.5194/acp-6-715-2006, 2006.

Menut L., Chiapello, I., and Moulin, C.: Previsibility of mineral dust concentrations: The CHIMERE-DUST forecast during the first AMMA experiment dry season, J. Geophys. Res.-Atmos., 114, D07202, doi:10.1029/2008JD010523, 2009.

Molina, M. J. and Molina, L. T.: Megacities and atmospheric pollution, J. Air Waste Manage. Assoc., 54, 644-680, 2004.

Monge, M. E., D’Anna, B., Mazri, L., Giroir-Fendler, A., Ammann, M., Donaldson, D. J., and George, C.: Light changes the atmospheric reactivity of soot, P. Natl. Acad. Sci., 107, 6605-6609, doi:10.1073/pnas.0908341107, 2010.

Muraleedharan, T. R., Radojevic, M., Waugh, A., and Caruana, A.: Emissions from the combustion of peat: an experimental study, Atmos. Environ., 34, 3033-3035, 2000.

Park, R. J., Jacob, D. J., Chin, M., and Martin, R. V.: Sources of carbonaceous aerosols over the United States and implications for natural visibility, J. Geophys. Res., 108, 4355, doi:10.1029/2002JD003190, 2003.

Pfister, G., Pétron, G., Emmons, L. K., Gille, J. C., Edwards,
D. P., Lamarque, J.-F., Attie, J.-L., Granier, C., and Novelli, P. C.: Evaluation of CO simulations and the analysis of the CO budget for Europe, J. Geophys. Res., 109, D19304, doi:10.1029/2004JD004691, 2004.

Pfister, G., Hess, P. G., Emmons, L. K., Lamarque, J.-F., Wiedinmyer, C., Edwards, D. P., Pétron, G., Gille, J. C., and Sachse, G. W.: Quantifying CO emissions from the 2004 Alaskan wildfires using MOPITT CO data, Geophys. Res. Lett., 32, L11809, doi:10.1029/2005GL022995, 2005.

Pfister, G. G., Wiedinmyer, C., and Emmons, L. K.: Impacts of the fall 2007 California wildfires on surface ozone: Integrating local observations with global model simulations, Geophys. Res. Lett., 35, L19814, doi:10.1029/2008GL034747, 2008.

Press, W. H., Teukolsky, S. A., Vetterling, W. T., and Flannery, B. P.: Numerical Recipes, 2nd edition, Cambridge University Press, 1992.

Rouil, L., Honore, C., Vautard, R., Beekmann, M., Bessagnet, B., Malherbe, L., Meleux, F., Dufour, A., Elichegaray, C., Flaud, J.M., Menut, L., Martin, D., Peuch, A., Peuch, V.-H., and Poisson, N., PREV'AIR : an operational forecasting and mapping system for air quality in Europe, B. Am. Meteorol. Soc., 90, 73-83, doi:10.1175/2008BAMS2390.1, 2009.

Roy, D. P., Boschetti, L., Justice, C. O., and Ju, J.: The collection 5 MODIS burned area product - Global evaluation by comparison with the MODIS active fire product, Remote Sens. Environ., 112, 3690-3707, doi:10.1016/j.rse.2008.05.013, 2008.

Schmidt, H. C., Derognat, C., Vautard, R., and Beekmann, M.: A comparison of simulated and observed ozone mixing ratios for the summer of 1998 in western Europe, Atmos. Environ., 35, 6277-6297, 2001.

Seiler, W. and Crutzen, P. J.: Estimates of gross and net fluxes of carbon between the biosphere and atmosphere from biomass burning, Climatic Change, 2, 207-247, 1980.

Sofiev, M., Vankevich, R., Lotjonen, M., Prank, M., Petukhov, V., Ermakova, T., Koskinen, J., and Kukkonen, J.: An operational system for the assimilation of the satellite information on wildland fires for the needs of air quality modelling and forecasting, Atmos. Chem. Phys., 9, 6833-6847, doi:10.5194/acp-9-68332009, 2009.

Stavrakou, T., Müller, J.-F., De Smedt, I., Van Roozendael, M., van der Werf, G. R., Giglio, L., and Guenther, A.: Evaluating the performance of pyrogenic and biogenic emission inventories against one decade of space-based formaldehyde columns, Atmos. Chem. Phys., 9, 1037-1060, doi:10.5194/acp-9-1037-2009, 2009.

Tarantola, A.: Inverse problem theory; methods for data fitting and model parameter estimation, Elsevier, 1987.

Turquety, S., Logan, J. A., Jacob, D. J., Hudman, R. C., Leung, F. Y., Heald, C. L., Yantosca, R. M., Wu, S., Emmons, L. K., Edwards, D. P., and Sachse, G. W.: Inventory of boreal fire emissions for North America in 2004: the importance of peat burning and pyro-convective injection, J. Geophys. Res., 112, D12S03, doi:10.1029/2006JD007281, 2007.

UNECE: Present state of emission data, ECE/EB.AIR/97, 2009.

Urbanski, S. P., Hao, W. M., and Baker, S.: Chemical Composition of Wildland Fire Emissions, in: Developments in Environmental Science, V. 8, edited by: Bytnerowicz, A., Arbaugh, M., Riebau, A., and Andersen, C., New York, Elsevier, 79-107, 2009.

van der Werf, G. R., Randerson, J. T., Giglio, L., Collatz, G. J., 
Kasibhatla, P. S., and Arellano Jr., A. F.: Interannual variability in global biomass burning emissions from 1997 to 2004, Atmos. Chem. Phys., 6, 3423-3441, doi:10.5194/acp-6-3423-2006, 2006.

van der Werf, G. R., Randerson, J. T., Giglio, L., Collatz, G. J., Mu, M., Kasibhatla, P. S., Morton, D. C., DeFries, R. S., Jin, Y., and van Leeuwen, T. T.: Global fire emissions and the contribution of deforestation, savanna, forest, agricultural, and peat fires (19972009), Atmos. Chem. Phys., 10, 11707-11735, doi:10.5194/acp10-11707-2010, 2010.

Vautard, R., Builtjes, P. H. J., Thunis, P., Cuvelier, C., Bedogni, M., Bessagnet, B., Honoré, C., Moussiopoulos, N., Pirovano, G., Schaap, M., Stern, R., Tarrason, L., and Wind, P.: Evaluation and intercomparison of Ozone and $\mathrm{PM}_{10}$ simulations by several chemistry transport models over four European cities within the CityDelta project, Atmos. Environ., 41, 173-188, 2007.

Vompersky, S. J., Sirin, A. A., Cyganova, O. P., Valjaeva, N. A., and Majkov, D. A.: Bolota i zabolochennye zemli Rossii: popytka analiza prostranstvennogo raspredeenija i raznoobrazija, Izvestiya RAN, Seriya Geograficheskaya, 5, 39-50, 2005.

Wang, J., Christopher, S. A., Nair, U. S., Reid, J. S., Prins, E. M., Szykman, J., and Hand, J. L.: Mesoscale modeling of Central American smoke transport to the United States: 1. "Top-down" assessment of emission strength and diurnal variation impacts, J. Geophys. Res., 111, D05S17, doi:10.1029/2005JD006416, 2006.

Wiedinmyer, C., Quayle, B., Geron, C., Belote, A., McKenzie, D., Zhang, X., O'Neill, S., and Wynne, K. K.: Estimating emissions from fires in North America for air quality modeling, Atmos. Environ., 40, 3419-3432, doi:10.1016/j.atmosenv.2006.02.010, 2006.

Witte, J. C., Douglass, A. R., da Silva, A., Torres, O., Levy, R., and Duncan, B. N.: NASA A-Train and Terra observations of the 2010 Russian wildfires, Atmos. Chem. Phys., 11, 9287-9301, doi:10.5194/acp-11-9287-2011, 2011.
Wooster, M. J., Zhukov, B., and Oertel, D.: Fire radiative energy for quantitative study of biomass burning: Derivation from the BIRD experimental satellite and comparison to MODIS fire products, Remote Sens. Environ., 86, 83-107, 2003.

Wooster, M. J., Roberts, G., Perry, G. L. W., and Kaufman, Y. J.: Retrieval of biomass combustion rates and totals from fire radiative power observations: FRP derivation and calibration relationships between biomass consumption and fire radiative energy release, J. Geophys. Res., 110, D24311, doi:10.1029/2005JD006318, 2005.

WRAP - Western Regional Air Partnership: Development of 200004 Baseline Period and 2018 Projection Year Emission Inventories, Prepared by Air Sciences, Inc. Project No. 178-8, August 2005.

Yokelson, R. J., Ward, D. E., Susott, R. A., Reardon, J., and Griffith, D. W. T.: Emissions from smoldering combustion of biomass measured by open-path Fourier transform infrared spectroscopy, J. Geophys. Res., 102, 18865-18877, 1997.

Yurganov, L. N., Rakitin, V., Dzhola, A., August, T., Fokeeva, E., George, M., Gorchakov, G., Grechko, E., Hannon, S., Karpov, A., Ott, L., Semutnikova, E., Shumsky, R., and Strow, L.: Satellite- and ground-based CO total column observations over 2010 Russian fires: accuracy of top-down estimates based on thermal IR satellite data, Atmos. Chem. Phys., 11, 7925-7942, doi:10.5194/acp-11-7925-2011, 2011.

Zaripov, R. B., Konovalov, I. B., Kuznetsova, I. N., Belikov, I. B., and Zvyagintsev, A. M.: WRF ARW and CHIMERE models for numerical forecasting of surface ozone concentration, Russian Meteorology and Hydrology, 36, 249-257, doi:10.3103/S1068373911040054, 2011.

Zvyagintsev, A. M., Belikov, I. B., Egorov, V. I., Elansky, N. F., Kruchenitsky, G. M., Kuznetsova, I. N., Nikolaev, A. N., Obukhova, Z. V., and Skorokhod, A. I.: Positive anomalies in the surface ozone concentrations in July-August 2002 over Moscow and its suburbs, Izvestiya, Atmos. Ocean. Phys., 40, 68-79, 2004. 